FHWA/IN/JTRP-2008/8

Final Report

PRACTICES FOR SEAMLESS TRANSMISSION OF DESIGN DATA FROM DESIGN PHASE TO CONSTRUCTION EQUIPMENT OPERATION A SYNTHESIS STUDY

Phillip Dunston

James Monty

May 2009 
Final Report

FHWA/IN/JTRP-2008/8

\title{
PRACTICES FOR SEAMLESS TRANSMISSION OF DESIGN DATA FROM DESIGN PHASE TO CONSTRUCTION EQUIPMENT OPERATION - A SYNTHESIS STUDY
}

\author{
by \\ Phillip S. Dunston, Ph.D. \\ Principal Investigator \\ and \\ James Monty \\ Graduate Research Assistant \\ School of Civil Engineering \\ Purdue University \\ Joint Transportation Research Program \\ Project No: C-36-67MMMM \\ File No: 9-10-90 \\ SPR-3131 \\ Prepared in Cooperation with the \\ Indiana Department of Transportation and \\ The U.S. Department of Transportation \\ Federal Highway Administration
}

The contents of this report reflect the views of the authors who are responsible for the facts and the accuracy of the data presented herein. The contents do not necessarily reflect the official views or policies of the Federal Highway Administration and the Indiana Department of Transportation. This report does not constitute a standard, specification or regulation.

Purdue University

West Lafayette, Indiana

May 2009 
TECHNICAL REPORT STANDARD TITLE PAGE

\begin{tabular}{|c|c|c|}
\hline $\begin{array}{l}\text { 1. Report No. } \\
\text { FHWA/IN/JTRP-2008/8 }\end{array}$ & 2. Government Accession No. & 3. Recipient's Catalog No. \\
\hline \multirow{2}{*}{\multicolumn{2}{|c|}{$\begin{array}{l}\text { 4. Title and Subtitle } \\
\text { Practices for Seamless Transmission of Design Data from Design Phase to } \\
\text { Construction Equipment Operation - A Synthesis Study }\end{array}$}} & $\begin{array}{l}\text { 5. } \quad \text { Report Date } \\
\text { May } 2009\end{array}$ \\
\hline & & 6. Performing Organization Code \\
\hline \multicolumn{2}{|l|}{$\begin{array}{l}\text { 7. Author(s) } \\
\text { Phillip Dunston and James Monty }\end{array}$} & $\begin{array}{l}\text { 8. Performing Organization Report No. } \\
\text { FHWA/IN/JTRP-2008/8 }\end{array}$ \\
\hline \multirow{2}{*}{\multicolumn{2}{|c|}{$\begin{array}{l}\text { 9. Performing Organization Name and Address } \\
\text { Joint Transportation Research Program } \\
550 \text { Stadium Mall Drive } \\
\text { Purdue University } \\
\text { West Lafayette, IN 47907-2051 }\end{array}$}} & 10. Work Unit No. \\
\hline & & $\begin{array}{c}\text { 11. Contract or Grant No. } \\
\text { SPR-3131 }\end{array}$ \\
\hline \multirow{2}{*}{\multicolumn{2}{|c|}{$\begin{array}{l}\text { 12. Sponsoring Agency Name and Address } \\
\text { Indiana Department of Transportation } \\
\text { State Office Building } \\
100 \text { North Senate Avenue } \\
\text { Indianapolis, IN } 46204\end{array}$}} & $\begin{array}{c}\text { 13. Type of Report and Period Covered } \\
\text { Final Report }\end{array}$ \\
\hline & & 14. Sponsoring Agency Code \\
\hline
\end{tabular}

15. Supplementary Notes

Prepared in cooperation with the Indiana Department of Transportation and Federal Highway Administration.

\section{Abstract}

The Indiana Department of Transportation (INDOT), in response to requests from the construction contracting community, has chosen to examine how to facilitate their contractors' use of three-dimensional machine control (3D-MC) systems, especially GPS-based systems. INDOT recognizes that the prerequisite 3D project model, if available in its intelligent electronic form, may be leveraged by both INDOT and its project partners to automate the performance of tasks other than construction. Therefore, INDOT was compelled to initiate this study to investigate the state of technology and the experiences of other state transportation agencies (STAs) and to synthesize that information to formulate recommendations for INDOT to implement for utilizing the electronic design file (EDF). The emphasis of the study is to discern best practices for how to facilitate better collaborative work and how to advance the use of 3D-MC on INDOT projects while avoiding or mitigating any pitfalls associated with supporting the use of the new technology.

The work plan conducted by Investigators from the Purdue University School of Civil Engineering involved a literature review to uncover information on performance of 3D-MC technologies and computer technologies and associated processes to enhance project team collaborations. Concurrently, the Investigators surveyed vendors of 3D-MC systems and contractors and designers to uncover critical lessons from their experience with these systems. A review of STA Web sites was conducted to gain an overview of STA requirements regarding design files and product offerings of two leading providers of project design and civil project management software were reviewed to assess the efficacy of EDF sharing. These reviews were compared against the INDOT Project Development Process to reveal opportunities to leverage electronic forms of the design files. Contacts established from the surveys and Web site reviews, yielded further contacts with engineering service providers and STA personnel who were primarily interviewed by phone. The STA contacts also provided or referenced documents that were valuable to the information gathering activity. The phone interviews and shared documents provided the greatest clarity regarding the progress of other STAs toward implementation.

The study confirmed that there are accessible commercial products from the industry leaders that enable 3D design model creation, secure file sharing with version control. Digital terrain models (DTMs) from these products can be read and translated for input to the array of GPS-based 3D-MC system options that are capable of meeting typical standard construction tolerances. The companies also have incorporated enough interoperability to work across platforms, thus enabling seamless and collaborative 3D-model-based project delivery with the appropriate investment. INDOT is making the correct investment in software applications to realize this objective.

With regard particularly to implementing 3D-MC, information from select STAs provided insight into options and considerations for project selection and specifications that clarify liability. STAs have assumed various positions of responsibility for making the DTM available to contractors, ranging from an official hands-off stance to one that prescribes GPS-based 3D-MC for certain projects. The Investigators encourage INDOT to pursue implementation through a program of pilot projects with special committee oversight responsible for assessing benefits and compiling lessons learned. A manageable set of objectives should be carefully set for each pilot project so that benefits can be convincingly demonstrated. Indiana design consultants seek leadership from INDOT and input from construction contractors regarding the critical data and information needs so that they can deliver the desired electronic design files with greatest efficiency and effectiveness.

17. Key Words

3D-MC systems, GPS, surveying, stakeless grading

18. Distribution Statement

No restrictions. This document is available to the public through the National Technical Information Service, Springfield, VA 22161

\begin{tabular}{|c|c|c|c|}
\hline $\begin{array}{c}\text { 19. Security Classif. (of this report) } \\
\text { Unclassified }\end{array}$ & $\begin{array}{c}\text { 20. Security Classif. (of this page) } \\
\text { Unclassified }\end{array}$ & 94 \\
\hline
\end{tabular}




\section{TABLE OF CONTENTS}

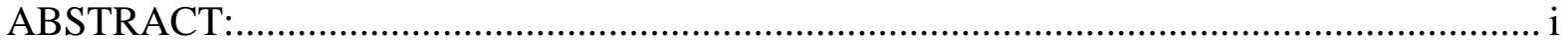

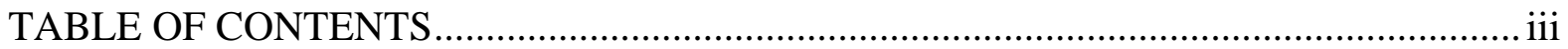

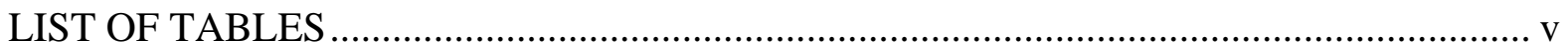

LIST OF FIGURES ………………………......................................................................

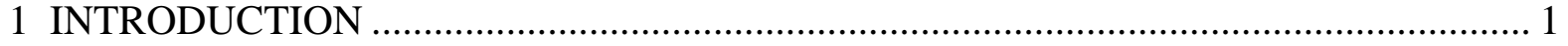

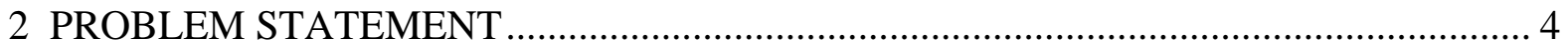

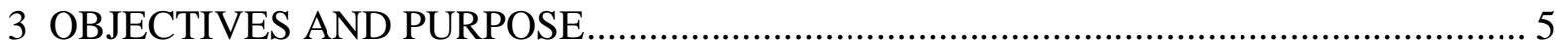

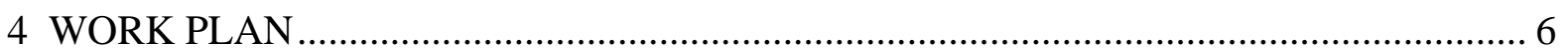

4.1 Task 1: Technology Literature Review and Initial Interviews ................................. 6

4.2 Task 2: Documentation of Project Information Process ............................................ 7

4.3 Task 3: Surveys/Interviews of Vendors and Practitioners ..................................... 7

4.4 Task 4: Identification and Responses to Professional/Contractual Liability and

Data Security Issues................................................................................................... 7

4.5 Task 5: Development of Draft and Final Report ……………………………........ 8

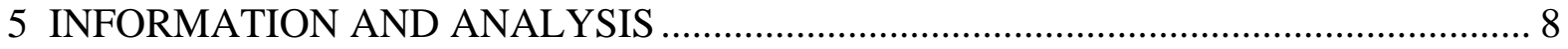

5.1 Technology Literature Review and Initial Interviews ................................................. 8

5.1.1 Three-Dimensional Machine Control .................................................................... 8

5.1.2 Electronic Design Files and Virtual Design and Construction .............................. 12

5.2 Enhancing INDOT's Project Delivery Process................................................................ 17

5.2.1 Outline of INDOT Project Development Process.................................................. 18

5.2.3 Software Tools for Project Delivery …………….................................................. 22

5.2.3.1 INDOT's Current Software Alignment ...................................................... 22

5.2.3.2 Autodesk Compatibility for Consultants ....................................................... 25

5.2.3.3 Summation Regarding Software Tools......................................................... 25

5.3 Information from Vendors and Practitioners .............................................................. 26

5.3.1 Technologies for 3D Machine Control ................................................................. 26

5.3.1.1 Trimble Navigation ............................................................................... 28

5.3.1.2 Topcon Positioning Systems ....................................................................... 29

5.3.1.3 Leica Geosystems ................................................................................... 29

5.3.1.4 Sequence of Tasks for Using 3D-MC ......................................................... 30

5.3.1.5 3D-MC System Costs .............................................................................. 31

5.3.1.6 3D-MC Alternatives Summation ................................................................... 32

5.3.2 STAs' Use of Electronic Design Files ................................................................. 33

5.3.2.1 Preparing, Submitting, and Sharing EDFs................................................... 34

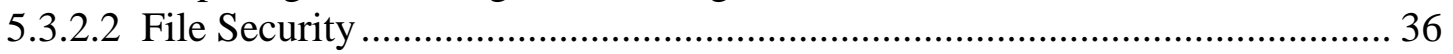

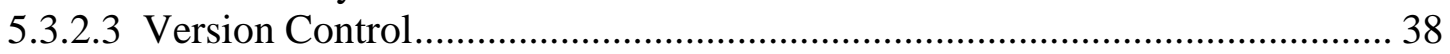

5.3.2.4 Savings and Costs of Utilizing 3D-MC and Providing EDFs ....................... 39

5.3.3 Overview of STA Progress Toward 3D-MC Implementation ............................... 43

5.3.3.1 Minnesota Department of Transportation ...................................................... 44

5.3.3.2 Pennsylvania Department of Transportation (PennDOT)................................. 45

5.3.3.3 Kentucky Department of Transportation ........................................................... 45

5.3.3.4 Florida Department of Transportation ……………………………………..... 46

5.3.3.5 Iowa Department of Transportation............................................................ 46

5.3.3.6 Georgia Department of Transportation.......................................................... 46 
5.3.3.7 Michigan Department of Transportation (MDOT) ..................................... 47

5.3.3.8 Washington State Department of Transportation ....................................... 47

5.3.3.9 New York State Department of Transportation .............................................. 48

5.3.4 INDOT Developments Regarding 3D-MC ................................................... 51

5.3.5 Additional Implementation Considerations Regarding GPS ............................. 53

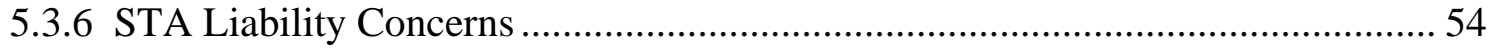

5.3.6.1 Liability Status Quo and the Insurer's Perspective.................................... 55

5.3.6.2 STA Liability in Directing Technology Utilization...................................... 56

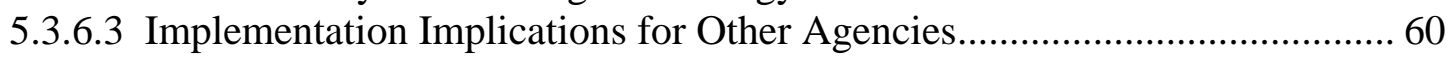

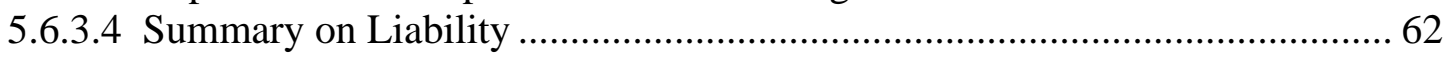

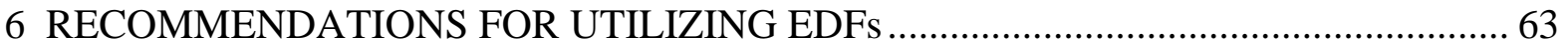

6.1 Continuing Software Adoption and Business Transformation ................................. 64

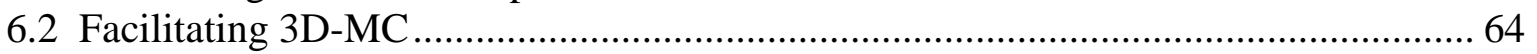

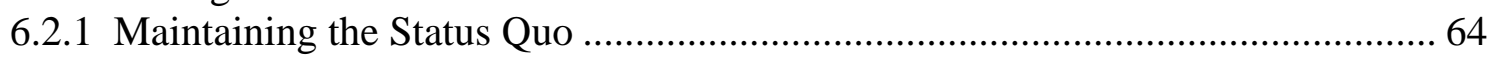

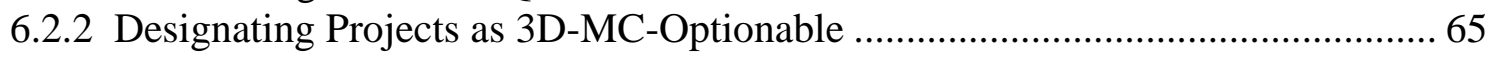

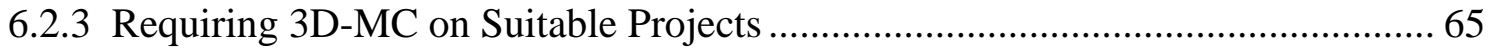

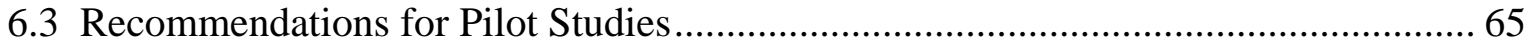

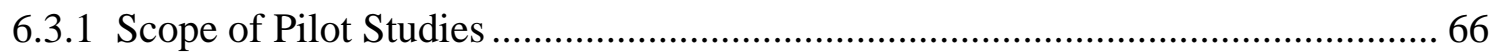

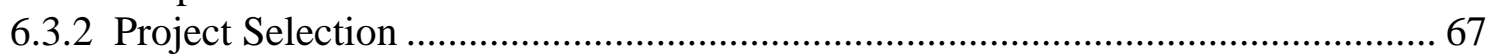

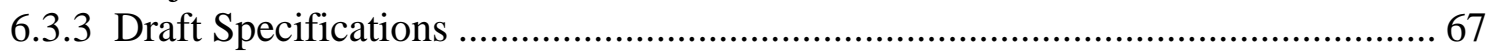

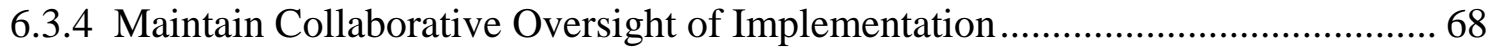

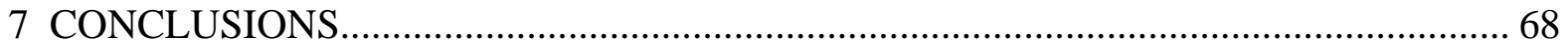

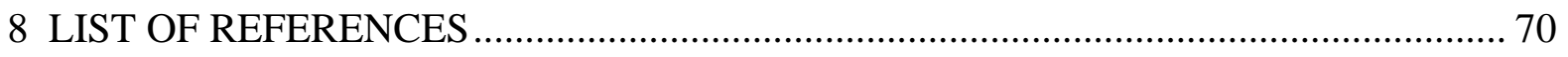

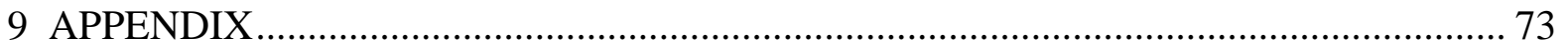




\section{LIST OF TABLES}

Table 1 Typical Examples of Benefits reported by Contractors from Utilizing 3D-MC ...... 40 Table 2 Gains Presented from Experience of One Tennessee Contractor over Numerous Projects (presentation by Bret Alsobrooks, Jones Bros., Inc., Mt. Juliet, Tennessee to AASHTO TIG; http://www.aashtotig.org)

Table 3 Project Benefits for Construction Cited During Interviews.................................. 42 


\section{LIST OF FIGURES}

Figure 1 Example of a compactor with the Trimble GPS-based 3D-MC system.................. 11

Figure 2 INDOT Project Development Process for Major Projects .................................... 19 


\section{INTRODUCTION}

Computational devices and applications make the creation of project design information in digital form a commonplace occurrence today, but standard practice regarding integration and workflow between project team members remains a challenge. For the sake of efficiency, it is desirable for the transportation construction industry to have a standard practice regarding software and protocols starting from defining the original topography of the land that is to be improved, through the planning and design processes, and on to the detailed estimating process and automated controls and inspection functions during actual construction. Such an approach aimed at the horizontal and vertical control of all elements that are to be built must work through different software and hardware platforms to facilitate seamless design data transmission across interfaces between entities in the project supply chain. Particularly in the case of earthwork, the most advanced machine guidance technologies for what is commonly called stakeless grading make it desirable that this information be readily available in electronic form from a 3D design model for import to global positioning system (GPS) guidance software and systems. If the standard of practice produces or facilitates production of the proper electronic design files (EDFs) at initial creation, all project stakeholders, and especially construction contractors, can eliminate the expenditure of time and resources in reproducing or drastically modifying the design information just to take advantage of the technologies that enhance productivity, quality, and safety performance. Recognizing this trend and the fact that it implies a new paradigm of project delivery, the Indiana Department of Transportation (INDOT) has determined to examine the current state of technology and lessons learned by others as a step toward planning its own approach for creating agency standards to facilitate more effective use of the electronic format of design models.

The move from a 2D view based process to a 3D model based process is a major paradigm shift that the construction industry at large is formally embracing as, specifically, the processes and tools for building information modeling (BIM) are being developed and employed on building projects. Supporting this trend, the Associated General Contractors (AGC) of America has released the first edition of its The Contractors' Guide to BIM, and researchers who have been involved in the academic and industry pursuits of the last three 
decades or so to realize this vision have recently released the first handbook available on the topic (Eastman et al. 2008). In the former publication, the alternative generic terminology, virtual design and construction (VDC), is mentioned as being increasingly used to describe the utilization of BIM (technology and processes). The key driver for this present study was a desire on the part of constructors of INDOT's projects to utilize automated machine guidance (AMG), typically in the form of GPS machine guidance or control systems, on projects they perform for INDOT. AMG, or 3D-MC (for three-dimensional machine control) as it is commonly called by manufacturers of such systems, involves the use of some sort of system that transmits 3D coordinate information to guide the navigation and work (tool operation) of construction equipment, either in the indicate (as visual guidance to the equipment operator) or the automatic (as direct input to drive the hydraulics controlling the equipment tool) mode. 3D-MC systems explicitly require that the user input coordinate data from a 3D model of the existing and planned topography. These technologies seem to be contributing the major pull away from a 2D view based process to a 3D model based process for the transportation construction industry.

A recently published National Cooperative Highway Research Program (NCHRP) Report, NCHRP Synthesis 372: Emerging Technologies of Construction Delivery (NCHRP 2007), documented the use of five emerging technologies poised to enable "smart jobsites" for transportation construction projects, one of which was the use of GPS particularly for layout, machine guidance, and quantity tracking. After describing the technology, the report characterized the technology in terms of benefits, extent of use, barriers to use, instances of successful implementation and procedures, unresolved issues, and unintended consequences. Lessons learned were collected from transportation agencies. Information was gathered from a broad literature review, interviews with subject matter experts, and survey of transportation agencies in the U.S. (41) and Canada (7). The growing interest in GPS-based 3D-MC and in this “smart jobsites” concept points toward the emergence of a version of VDC for the civil infrastructure industry. In the face of public and political encouragement to reduce infrastructure construction costs, such an evolution in technology and practice very likely would be welcomed eagerly by the stakeholders in transportation construction projects.

The improving power and capabilities of computer technology has long inspired confidence in the advent of a day that will be marked by offices doing their work paperlessly, 
and improved bandwidth on the Internet yet promises to improve collaboration by making it easier for workers to share information. Currently, design software from leading companies such as Autodesk, Inc. and Bentley Systems, Inc. have fulfilled the promise of enabling highway design work to be done via software. A main advantage of computer aided drafting and design (CADD) packages is the ability to quickly edit a design as well as to try "what if" scenarios quickly on the screen. A user can easily add and delete elements of a design until the desired result is achieved. Another desired software technology benefit to the design and construction industry firms as well as to owner organizations is the ability to quickly and easily share EDFs, which is facilitated by software vendors developing electronic file sharing environments emphasizing security of documents and interoperability between applications. This improves the design-build process which can ultimately save all the stakeholders time and money.

File sharing allows for quick and seamless collaboration, reducing the time a project remains on the drawing board. It also will allow project development to become more efficient and cost effective. Electronic delivery also allows the design consultant to send the files to the state for each design stage review. Theoretically, this should streamline the process for the state to perform the review processes. With properly constructed layers of information, tasks such as utility checking and right of way property assessments could be performed in less time. CADD software also now provides for reviewers to redline on the electronic version of the plans, and to share these edits with the designer. This saves money in the continuous reprinting of plans which wastes paper and other paper document reproduction resources.

Cost estimation is a use of the design file that can be taken advantage of by the construction industry, but also is a use which typifies the need for careful use of the CADD software. By comparing a layer representing the current ground surface with that of the designed surface, the software can provide accurate estimates for the amount of earth required to be moved. Additional material estimates, such as paving material, reinforcement steel, and drainage culverts, for example, can all be obtained from the software. The designer or STA can more consistently produce accurate quantity takeoffs for the engineering estimate, and the contractor is likewise enabled to arrive at a more accurate estimate of costs 
in a more timely fashion when they can automatically calculate quantities from EDFs than they can from paper plans or image formats such as the Portable Document Format (PDF).

At the same time, there can be a mistrust of this technology, as there can be a multitude of problems which the user is powerless to stop. For something as critical as construction drawings, designers want assurances that their work will be received and used exactly as they designed it at their desk. Before an engineer signs off on documents, they need to know that said documents are secure and that they will not become liable for modifications or misuses introduced by other parties. The inability to resolve these two problems inhibits some designers and engineers from taking full advantage of working in a truly digital environment.

One increasingly strong motivation for having these design files in a digital format is their use with GPS technologies. The use of GPS in providing machine guidance in the mining industry emerged at the end of the $20^{\text {th }}$ century, and has since been adopted in construction, primarily in earthwork operations. Pilot projects have been performed in several states, on a variety of tasks, including non-critical areas such as golf course grading and retention pond construction, to the grading of new road surfaces (Jonasson et al. 2002; Garret 2007). The analysis of data from these projects is being studied, and there is interest in the costs and benefits from using GPS-based machine guidance and in the broader issues surrounding development and use of the EDFs that are the necessary input to such systems.

\section{PROBLEM STATEMENT}

As a public agency, INDOT is motivated to advance its abilities to deliver projects both with greater efficiency and enhanced quality. Toward that end, INDOT seeks to work cooperatively with industry providers of design and construction services to identify and adopt value-adding technologies and processes to the project delivery process (PDP). Indiana transportation construction contractors have begun adopting GPS-based machine guidance systems for their equipment and have requested INDOT to consider facilitating access to the electronic project design files which would help contractors accelerate their preparation for earthmoving activities and thus maximize the full range of gains from the GPS-based machine guidance systems. Having been requested to consider this question, 
INDOT has recognized the broader question regarding the value, costs, and benefits of using the EDFs to accomplish other functions in the PDP with greater efficiency. This study was therefore initiated to look into what technology was currently in use in state highway construction, what practices were already established, and how Indiana could learn from what was already in place, in essence, a synthesis study of STA practice in the use of EDFs and facilitation of GPS-based 3D-MC on transportation projects. By looking at what has already and is being done, INDOT can establish its own set of best practices and avoid or mitigate any pitfalls associated with supporting the use of the new technology.

As with most new technology, construction companies have, in general, been hesitant to purchase GPS equipment until they could be sure that the costs of the equipment could be recouped. As more reports come out of the advantages companies have realized, the potential of companies making purchases increases. Rather than trying to catch up to the issues of the technology, it is better for transportation agencies such as INDOT to be aware of problems and have standards in place so designers and contractors both know what to expect.

\section{OBJECTIVES AND PURPOSE}

The goal of this project was to conduct a synthesis study to document the current state-ofpractice among STA's regarding the creation and use of electronic project design documents, especially to include the consideration of (1) the data needs of contractors using GPS machine guidance systems on their earthmoving equipment, (2) the standards, codes, and permitting concerns of the STA, (3) the professional liability and project information security concerns of the project team members, and (4) cost considerations with regard to implementation. The study was intended to provide INDOT, their engineering consultants, and construction contractors with information and options for implementing a procedure for utilizing electronic project design files in the development and delivery of INDOT projects, especially with an eye toward facilitating the new GPS-based automated machine guidance.

The proposed synthesis study is intended to fulfill the following objectives: 
1. Document knowledge regarding the software, hardware, and process solutions for creating, collecting, transforming, translating, and transmitting project data that can be used ultimately by GPS-based construction equipment guidance systems, including clarification of the interface hurdles between companies/entities.

2. Characterize how the standards, regulations, codes of practice, and cost constrain the use of electronic project files for procuring transportation projects and how STAs have or are dealing with such constraints.

3. Make recommendations to INDOT for implementation of procedures for developing and executing transportation projects using EDFs.

\section{WORK PLAN}

The work plan was devised to assess the complete flow of information, from the inception of the job to the very end including actual field layout through the use of GPS. Furthermore, the investigation was intended to identify software and hardware packages that provide a seamless (or close to seamless) transfer of the data through different phases of the design and construction process.

\subsection{Task 1: Technology Literature Review and Initial Interviews}

A literature review was conducted in order to determine the published state-of-the-art and state-of-the-practice regarding (1) the use of GPS systems to automatically guide or control construction equipment operation and (2) the utilization of electronic forms of the design files in the process of procuring construction projects. This review included scholarly publications, technical reports and other special documents, construction industry trade periodicals, and the published product information from vendors of GPS machine guidance systems. Information from literature on virtual design and construction was added under this task as its importance was recognized during the course of the study. The information from this task is presented under Section 5.1 of this report. 


\subsection{Task 2: Documentation of Project Information Process}

The investigators documented the process of project design data collection, organization, distribution, use, and modification for INDOT projects in the context of agency standards, technological, and legal requirements. This task revealed the flow of information and the number of transfers of information that must occur, and noted the capabilities of software technology currently utilized by INDOT.

\subsection{Task 3: Surveys/Interviews of Vendors and Practitioners}

Vendors of GPS machine guidance/control systems were contacted to obtain the most up-todate description of commercially available systems, and consultants, contractors, and engineering service providers (firms providing computational support services to designers and contractors) were subsequently surveyed to balance advertised capabilities with user experience. Contractors and design consultants were surveyed to document their experience with the preparation, distribution, and effective use of project data in electronic format. These interviews and surveys provided an overview of commercial software options and data and file formats that are encountered in practice and experiences regarding their advantages and disadvantages. Cost parameters were not often divulged but were noted when provided.

\subsection{Task 4: Identification and Responses to Professional/Contractual Liability and Data Security Issues}

INDOT managers and design consultants and engineering service providers were interviewed to identify concerns regarding data security and professional liability associated with the utilization of electronic project design media. Other STAs that are identified as having or developing procedures for using electronic design documents were included for their insights and experiences with these issues. 


\subsection{Task 5: Development of Draft and Final Report}

Finally, this report has been drafted to incorporate the findings of Tasks 1-4 into an overview of technologies and approaches for how STAs, designers, and construction contractors utilize electronic design documents to develop and deliver transportation projects, particularly when GPS-controlled construction equipment is used in the field. It culminates in recommendations for how INDOT can proceed toward implementing procedures for utilizing EDFs for project development and delivery.

\section{INFORMATION AND ANALYSIS}

This section of the report addresses the various aspects of this study topic as they were revealed through execution of the work plan. Since this study is primarily an attempt to capture the state-of-the-art and the state-of-the-practice, the "data” as such is qualitative and anecdotal, rather than scientific, in nature. As much as possible, opinions not based upon specific experience have been either conveyed clearly as such or avoided altogether. Each subsection concludes with elaboration of the significance of the assembled information.

\subsection{Technology Literature Review and Initial Interviews}

The review of literature focused on three general areas, GPS machine guidance and EDFs, and virtual design and construction. Only the first two topics were included in the original work plan. The third was deemed by the Investigator to be relevant after further reflection on the absence of academic research on the use of EDFs in transportation construction projects. This more general topic was deemed important to the vision projected by the aims of the study.

\subsubsection{Three-Dimensional Machine Control}

The results of a search of academic research literature on 3D-MC under its various names for guidance, control, or monitoring of construction equipment, revealed a focus on technical performance, such as demonstrations of the higher precisions afforded by real-time- 
kinematic (RTK) GPS and the practical feasibility of a proposed control or monitoring scheme, rather than benchmarking performance. There are several early research articles, such as those authored by Oloufa et al. (1997), Tserng and Russell (1997), Do et al. (1999), Tserng et al. (2000), and Peyret et al. (2000), addressing various technical hurdles (hardware and computational algorithms) associated with using GPS technology to guide or track construction equipment. At the stage of technological progress represented by their work, researchers tended not to conduct comparisons with conventional methods because of the unfinished development stages of the technologies they were exploring. Even since GPS AMG technology has become commercially available for construction, very little research that deals with technology performance and cost comparisons has appeared in the scholarly literature. Daoud (1999), Jonasson et al. (2002), Flinn et al. (1999), and Flinn and Fileccia (2006) represent the small number of academic evaluations of commercially available technologies that aimed to analyze and document performance impacts from adopting 3DMC technologies such as laser or GPS. Results reported by these studies were based on analyses of limited case studies and pointed toward improvements from laser and GPS guidance. Daoud (1999) and Jonasson et al. (2002), however, were in agreement that approximately $30 \%$ increases in productivity could be expected under their assumed scenarios, and corresponding decreases in direct unit cost were attributed to both productivity improvement and reduced labor requirements for surveying and grade checking. Flinn et al. (1999) and Flinn and Fileccia (2006), discussing benefits for the mining industry, described particular advanced commercial systems that utilize GPS and other communications technology and real-time monitoring capabilities for total mining fleet operations management and referred to generic benefits without citing figures. Even if they had, it should be recognized that the high investment cost for such extensive systems thus far has prohibited marketing for roadway construction, so their reported benefits are not yet fully available for the construction industry. Outside of the type of studies represented by the two latter articles, studies by researchers are more focused upon comprehensive operational or site control for construction, looking ahead to the vision of a more fully automated jobsite and demonstrating the technical feasibility and challenges for new multi-technology control applications such as described in work by Bernold (2002), Oloufa et al. (2003), Navon and Shpatnitsky (2005), and Makkonen (2006). In summary, scholarly research has not provided 
firm, substantial quantitative guidance regarding the magnitudes of impacts from implementing 3D-MC in construction, and rarely has it sought to do so.

Rather, it is articles from trade magazines, usually not very extensive, that are framed to tout the capabilities enabled by the technology and the promise of associated performance and cost benefits (Fiscor 2000; Brown 2001; Zeyher 2002; Anon 2005; Hampton 2005; Garrett 2007). However, such examples tend to be brief coverage spotlight articles and are not documented in a fashion that allows for benchmarking of performance gains. Zeyher (2002) does quote a generic expectation of contractors cutting between 15 and $30 \%$ out of their costs for earthmoving and preparation phases. The clear general conclusion that can be drawn, however, is that contractors are expressing satisfaction regarding their technology investment and have been able to deliver projects faster in part due to accelerated operations and have seen bottom line impacts primarily due to reduced labor costs for surveying and grade checking. Also, and very important, accuracy and precision have proven adequate to satisfy conventional quality standards. One caution regarding the technology is the often time-consuming task of preparing the required 3D terrain model from original 2D design documents (Anon 2005), thus underscoring a key motivation for this study.

The market, however, for 3D-MC systems and their utilization in construction indeed appears to be growing as one surveys the literature. The three leading providers have remained the same for a number of years: Trimble Navigation, Ltd., Topcon Positioning Systems, Inc., and Leica Geosystems. A compactor equipped with the Trimble GPS-based 3D-MC system is depicted in Figure 1. In this setup, two GPS receiver antennae are mounted on the opposite ends of the dozer blade. It is estimated that Trimble has about $70 \%$ of the GPS-based 3D-MC market, dominating perhaps as a direct result of their successful partnership with Caterpillar, Inc. to develop 3D-MC for the mining and then construction markets during the 1990s. While Topcon and Leica possess most of the remaining market, there are a number of other players who have specialized equipment for 3D-MC (Zeyher 2002). Both Zeyher (2002) and Hampton (2005) make it clear that contractors have been the ones taking the lead in adopting 3D-MC technology and thus placing pressure on the other project partners and the design software industry to catch up and adopt the necessary changes in technology and practice to better facilitate stakeless grading. Software developers, such as Bentley Systems, Inc. which provides the design software that is used by practically all 
STAs, has already begun to respond to the call for a 3D design model. Construction equipment manufacturers have responded by working with the 3D-MC manufacturers to manufacture construction equipment with their systems installed. Even early in the commercial emergence of the technology, Leica was already thinking of open architecture that allows the mixing and matching of components from different makers, a definite indication that they could see the market becoming firmly established (Fiscor 2000).

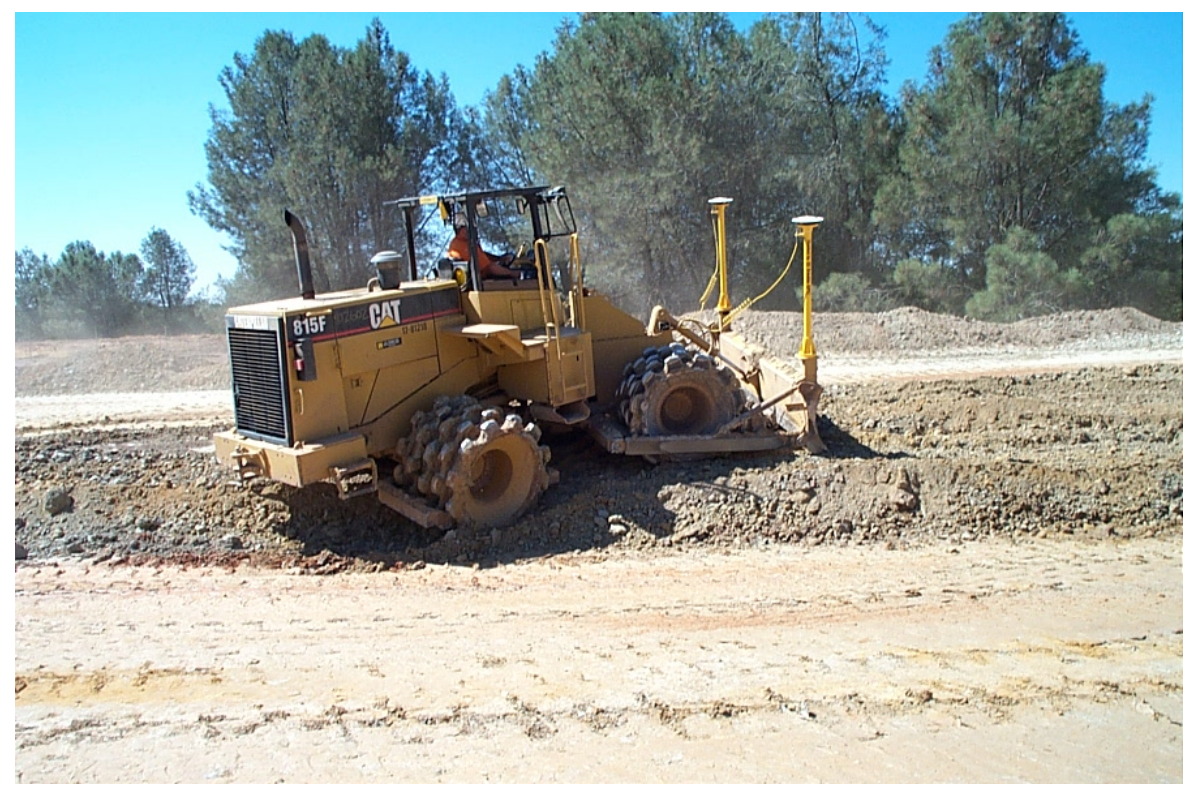

Figure 1 Example of a compactor with the Trimble GPS-based 3D-MC system

Based upon the review of literature regarding 3D-MC, the market for 3D machine control is only growing and more contractors can be expected to adopt the technology to remain competitive. Any agency that procures transportation construction projects may move confidently to work with formulating design and procurement practices to facilitate the use of 3D-MC on its projects since contractors, system developers, design software developers, and construction equipment manufacturers have already formed partnerships and invested in the technology. 


\subsubsection{Electronic Design Files and Virtual Design and Construction}

There is also a scarcity of academic, or trade, literature that gives direction on the use of EDFs in the construction industry. Any information discovered has tended to be anecdotal from the STAs themselves, or from interviews with firms which are responsible for the preparation of the files for use in machine guidance. When it comes to leveraging the EDF, this investigation found the most valuable information to be related to advances achieved for building construction. For the purposes of this study, EDF, refers to the intelligent electronic design file, i.e., a format which contains the active parametric design project data and not an image format such as PDF, TIFF, etc. While the latter are also electronic formats which do have their value, as this study will point out on occasion, this study draws a distinction between these passive formats and others from which project data may be automatically extracted by the appropriate software applications. This distinction is in keeping with the motivation to facilitate adoption of machine control technologies. In the review of STA practices, the use of the broader term electronic file (EF) denotes either the EDF or an image file format.

VDC, as mentioned in Section 1, is a term used almost interchangeably with BIM although it is actually a generic terminology for a model-based computer-supported project delivery process. BIM has been defined by the AGC in its Contractor's Guide to BIM (AGC 2006) as follows:

Building Information Modeling is the development and use of a computer software model to simulate the construction and operation of a facility.

The BIM Handbook (Eastman et al. 2008), two definitions are offered. The first one from the authors, is stated as "a modeling technology and associated set of processes to produce, communicate, and analyze building models.” The alternate definition, taken from Campbell (2006), states that BIM is 'an intelligent simulation of architecture' which enables integrated delivery and must exhibit the following six key characteristics:

- Digital,

- Spatial (3D),

- Measurable (quantifiable, dimension-able, and query-able), 
- Comprehensive (encapsulating and communicating design intent, building performance, constructability, and include sequential and financial aspect of means and methods),

- Accessible (to entire AEC/Owner team through an interoperable and intuitive interface), and

- Durable (usable through all phases of a facility's life).

Fortner (2008) points out that in its most sophisticated form, BIM combines all the documents, data, and software packages used during design, construction, and operation and management into a single electronic source. Thus, BIM should be recognized as both technology and process applicable to the entire project life cycle, while VDC properly applies only to the utilization of BIM to design and construct the building.

Another important term is BIM authoring tools, which refers to technologies by which users can produce building models that consist of parametric objects (Eastman et al. 2002). In order to support the project team collaboration required of the BIM process, open interfaces are necessary to allow the import of data for creation and editing of a design and export of data in various formats suitable for import to other applications and workflows. In its ideal form, BIM promises a dramatic change in the design and construction process, delivering virtually seamless acquisition and sharing of information and providing the basis for both new construction capabilities and changes in the roles and relationships among members of a project team.

Benefits from implementing BIM for the entire project life cycle are listed in the BIM Handbook as follows:

Pre-Construction Benefits to the Owner

- Concept, feasibility and design benefits

- Increased building performance and quality

Design Benefits

- Earlier and more accurate visualizations of a design

- Automatic low-level corrections when changes are made to design

- Generate accurate and consistent 2D drawings at any stage of the design

- Earlier collaboration of multiple design disciplines 
- Easily check against the design intent

- Extract cost estimates during the design stage

- Improve energy efficiency and sustainability

Construction and fabrication benefits

- Synchronize design and construction planning

- Discover design errors and omissions before construction

- React quickly to design or site problems

- Use design model as basis for fabricated components

- Better implementation and lean construction techniques

- Synchronize procurement with design and construction

Post Construction Benefits

- Better manage and operate facilities

- Integrate with facility operation and management systems

The Contractor's Guide to BIM (AGC 2006) provides a shorter, non-exhaustive list of benefits specifically for contractors:

- The ability to identify collisions (e.g., identifying ductwork running into structural members)

- The ability to visualize what is to be built in a simulated environment

- Fewer errors and corrections in the field

- Higher reliability of expected field conditions, allowing for opportunity to do more prefabrication of materials offsite, which is usually a higher quality at a lower cost

- The ability to do more "what if" scenarios, such as looking at various sequencing options, site logistics, hoisting alternatives, cost, etc.

- The ability for non-technical people (clients, users, etc.) to visualize the end product

- Fewer callbacks and thus, lower warranty costs

While early projects for which BIM was implemented were high-profile projects of rather significant size and great complexity of design, today BIM is being employed also on smaller 
building projects as more designers, contractors, and owners gain experience and are preferring the new way of delivering projects (Fortner 2008).

Demonstrating how a public owner agency can take the lead in embracing new technologies, the General Services Administration (GSA) has taken the plunge into adoption of BIM (Anon 2008). In July 2003, GSA established the National 3D-4D-BIM Program which has led over 30 pilot projects in its capital program. GSA now mandates a minimum requirement for BIM on their projects, and that mandate is fulfilled through collaboration with architects, BIM-authoring vendors, BIM-analysis vendors along with other typical participants in project planning and implementation. Before going to agency-wide adoption, the GSA relied on over 20 pilot projects just to make the business case for BIM applications. Specific efficiency gains were clearly established as a basis for establishing the current BIM requirements. Now, over 70 GSA projects have utilized BIM technology and processes.

BIM adoption does not occur without its challenges. The BIM Handbook cites three in particular:

- Selecting and/or developing software and data integration methods to support collaboration and teaming

- Clarifying who owns the multiple design, fabrication, analysis, and construction datasets; who pays for them, and who is responsible for their accuracy

- Project team members adapting to changes in practice and the use of information Fortner (2008) also adds that BIM adoption involves an intense learning curve associated with learning to utilize new authoring tools.

Since BIM is meant to yield benefits for all phases and partners on the project, it is a straightforward conclusion that the sooner the project team begins collaborating to develop the digital building model and share the information, the greater the benefits to be realized. Thus project delivery methods, such as design-build, that bring the major players of the project team together early in the project are the ones which facilitate the maximization of BIM benefits, although any method of delivery may benefit to some degree. It has been noted even by contractors who have gained significant experience with BIM that keeping the model updated is a job unto itself and that this function is something which should be explicitly planned. 
The BIM Handbook recommends seven critical steps to address the major issues when implementing BIM:

- Assign top level managers to a BIM adoption planning team to addresses all aspects of business and consider its impacts to internal units and external entities.

- Establish internal team of key manager implementers guided by cost, time and performance budgets set by the planning team.

- Start using BIM on one or two small projects (perhaps even completed projects) in parallel with existing technology and produce traditional documents from the building model to reveal deficiencies and provide educational opportunities.

- Use initial results to educate and guide continued adoption of BIM software and additional staff training, while keeping senior management apprised of progress, problems, insights, etc.

- Apply BIM to new projects and begin working with outside members of project teams to facilitate early integration and knowledge sharing through the building model.

- Continue to incorporate BIM in all aspects of the organization's functions and reflect the new business processes in contractual documents.

- Periodically re-plan the BIM implementation process to reflect the observed benefits and problems and set new goals for performance. Continue to extend BIM-facilitated changes to new locations and functions within the organization.

An additional question addressed by The Contractor's Guide to BIM (AGC 2006) is who should pay for the model. Philosophically, they advocate that the cost should be shared by all parties since the benefits are shared by all the project parties. They further advise that experience shows that a 6 to 18-month learning curve may be expected during which time cost might exceed benefits and some productivity might be lost, but that subsequent performance improvements justify these early transition sacrifices.

This discussion of BIM and VDC serves the purpose of highlighting the path that the civil sector of the construction industry may now follow since the building sector is successfully well on its way. Acknowledging distinctions with the building industry, the infrastructure industry should perhaps pursue realization of a Civil facility Information 
Modeling — or CIM for short-paradigm as its own version of the BIM concept, while the more encompassing VDC terminology can be directly adopted. The leading design software vendors, Autodesk, Inc. and Bentley Systems, Inc., have both invested in the BIM concept, and their current steps toward 3D modeling for transportation projects are well aligned with this notion for that industry sector. The strong early collaboration aspect, while less easily facilitated in the public sector, is something that is already becoming more feasible as STAs are expanding their project procurement options to include design-build and various forms of public-private partnerships. While there is yet a need for many more developments in technology and practice to realize this vision for the infrastructure sector, the lessons learned by the building sector should be noted and applied as implementation of this new approach to project delivery is pursued. One STA representative has described the new paradigm in the following manner: “... moving from 3 [views] of 1 [design] to 1 [design] of 3 [views].” In the current practice, the design becomes a cross-section-focused set as design details are fine tuned and corrected/updated and the base design model is sometimes not updated accordingly. Project design by 3D modeling keeps the focus on a complete accurate model.

\subsection{Enhancing INDOT's Project Delivery Process}

Having made the general case for pursuing the paradigm shift from a 2D paper based project delivery to one that is more automated and exploits 3D modeling, it follows that the project development process (PDP) for INDOT should be reviewed for opportunities to leverage electronic tools to utilize in the collection, generation, and transmission of project design information. As a basis for discussion, this study references the INDOT PDP for major projects as outlined by the INDOT Division of Production Management, within the Office of Project Management. Examination of this model reveals opportunities for leveraging digital tools to assist implementation of the PDP. Such opportunities then can be correlated to commercially available software tools, and new solutions may be pursued to bridge gaps between those existing tools. Sections 5.2.1 - 5.2.3 present this discussion. 


\subsubsection{Outline of INDOT Project Development Process}

The PDP model depicts twelve primary steps, with varying numbers of individual tasks, which serve as the focus for this analysis. Figure 2 depicts the PDP as a simple linear flowchart with indication of steps in the PDP where one of the two possible electronic forms of the design file (PDF or EDF) would be desirable. Paper copies are not indicated but are assumed to be printable from PDF versions when preferred.

Steps $1-5$ all involve preliminary fact finding and analysis tasks which do not produce any hard design, and therefore are not important to the discussion of EDFs. The key is to identify any step which requires or implies an addition to (further development of) some version of the design or analysis that requires extraction of data from the design model. At most, a project depository and sharing/retrieval resource is desired for steps 1-5. Finally, it is also indicated that an outside design consultant is assumed to be creating the design.

Step 6 - Develop Preferred Alternative - Stage 1 Design (0\%-30\%)

The first element of a hard design occurs during this step. Specifically, a 30\% detailed design is completed during this stage. Involved in this step are subsurface utility engineering (SUE), pavement design, and defining elements in the design to avoid environmental impacts. A significant amount of surveying activity (ground or aerial) and subsurface investigation occur during this step and feed into the design details. Automatic data collection and import of this data into the electronic design environment is a desirable capability. Reviews at this stage for design exceptions, value engineering, and constructability are notable tasks that will require copies of the design be shared with different entities both inside and outside INDOT. However, these reviews should not require EDFs; a PDF will suffice, and a paper copy, when preferred, can be printed from that format. Utility verification of location information requires sharing of the design with an outside organization (other than the consultant and INDOT), and the ability of utility companies to utilize digital files might speed the process. Finally, a cost estimate update occurs during this stage and might be facilitated by electronic quantity estimation, assuming such can be accomplished by software with a design at this degree of completion. A read-only file might be utilized. 


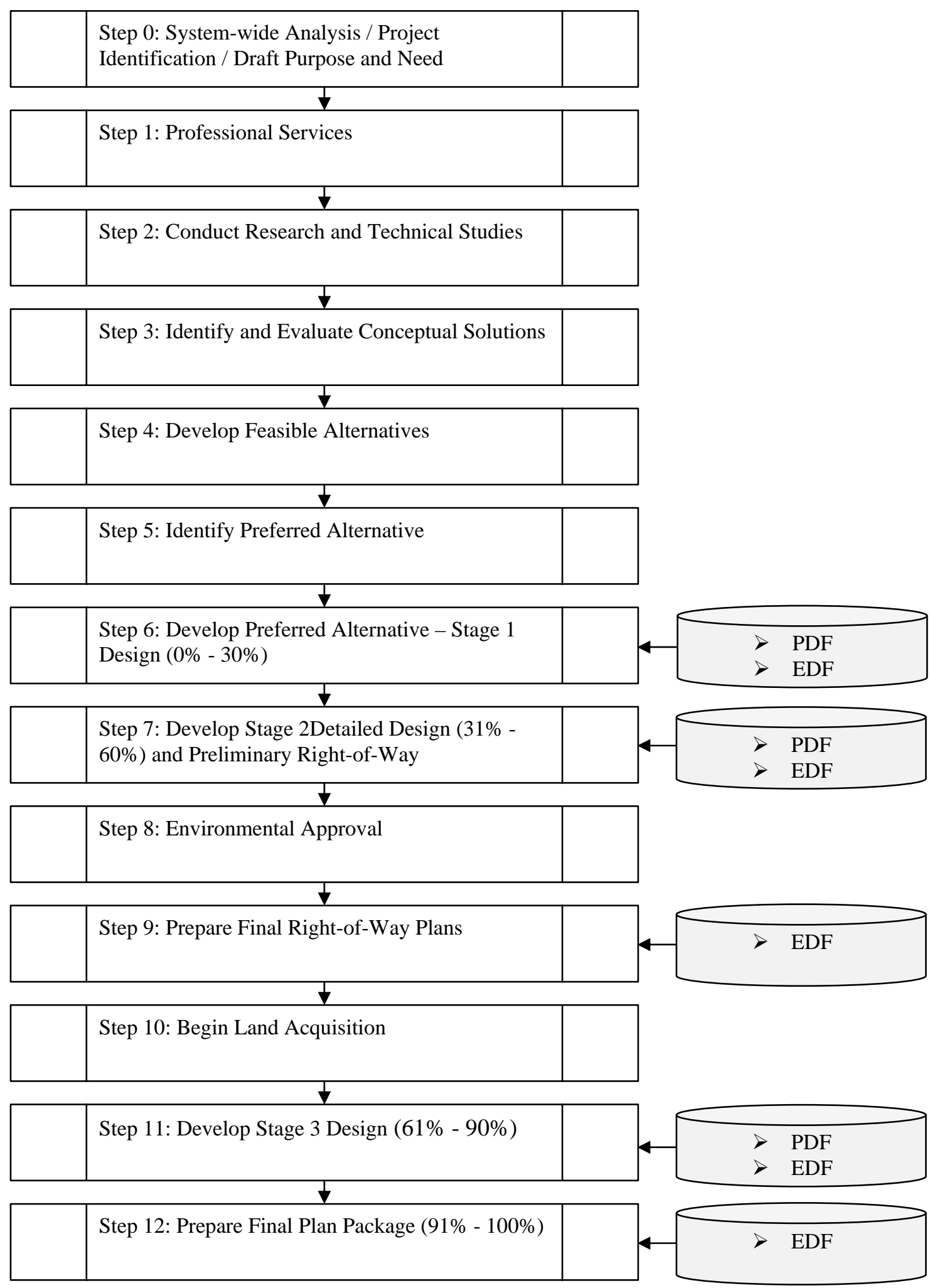

Figure 2 INDOT Project Development Process for Major Projects 
Step 7 - Develop Stage 2 Detailed Design (31\%-60\%)

During this step, utility conflicts are identified addressed and the preliminary right-of-way (ROW) plan is devised and reviewed. This step may benefit from handing off the design files internally for the preparation of ROW plans and the updating of property abstracts. It could be feasible to complete this step with hard copies, but there may be metrical information on the ROW contained in the EDF that may be helpful. The actual review of the design might be accomplished through distribution of the design in PDF form. Again, the cost update might be facilitated by quantity estimates performed automatically from a readonly version of the EDF.

Step 8 - Environmental Approval

A number of administrative tasks occur during this step and it appears that there should not be any need for the electronic files to change hands.

\section{Step 9 - Prepare Final Right-of-Way Plans}

This step consists of two parts, the preparation of the final ROW plans and engineering, and their review by INDOT. This step would require the set of ROW plans to be submitted from the design consultant to INDOT. Since they are considered a final set of plans, this might be the first step where electronic design file integrity critically comes into play. There will need to be a way for the engineer to "seal" the plans, and methods taken to ensure that any changes made to the ROW plans, either deliberate or accidental, can be detected. Methods to digitally secure and sign the files exist and will be discussed later.

\section{Step 10 - Begin Land Acquisition}

This step involves several administrative tasks, and there appear to be no design file requirements for utilizing the EDF.

\section{Step 11 - Develop Stage 3 Design (61\%-90\%)}

Any changes or enhancements required from the review at the end of step 7 would need to be made in this step. Notable activities that would involve specific reference to or scrutiny of the design are completion by the utilities of their utility relocation designs and review by 
INDOT of the associated plans, performance of the stage 3 design review, and conducting the final constructability review for the project. There should be no concerns of EDFs changing hands at this point unless the utility relocation design requires updated information on the INDOT project design. It is conceivable that having access to the EDF might save time if any significant changes have occurred. The reviews can be done without an EDF, but might utilize PDF versions of the design.

Step 12 - Prepare Final Plan Package (91\%-100\%)

This will be the most critical stage for the integrity of the design files. The final design files will be submitted by the design consultant to INDOT, and would first need to be inspected and sealed by the design firm's engineer. After they are, and electronic forms of the plans will need to be protected against modification. As noted above, an EDF would be helpful for performing the final construction cost estimate

The Final Project Document Review might be accomplished with hardcopies of the design, and the data integrity would not be called into question. The final step is the submission of the project documents to the Contracts Division. This is listed on the timeline as only taking one day, and lists only project documents. The only concern at this point is that the contract was fulfilled by the designers, and that the contract division would get the report. From here, the EDFs could be provided to bidders for estimating and then to the awarded contractor for preparation for use in project control, including 3D-MC.

This overview of the PDP reveals that opportunities for using some version of the design files either in their intelligent EDF form or in a simple PDF form. To have the EDF version available for various tasks during the development process that require the extraction of metrical information may yield significant time savings. Prior to construction, the EDF has potential value to field survey data input, right-of-way, cost estimating, utility location verification and relocation designs. It appears that other tasks drawing upon the design information can be performed by reference to a paper or PDF copy. Manual entry of information from paper or locked electronic copies of the design is inefficient compared to computer automated extraction from the appropriate design file (or associated database). 
Having established these opportunities, the next issue to examine is what commercial tools exist to meet the need.

\subsubsection{Software Tools for Project Delivery}

The two primary design software solutions for civil engineers come from Bentley Systems, Inc. and Autodesk, Inc. Both are important in this context because, while the vast majority of STAs have standardized around Bentley software solutions, many civil engineering and land development design consultants may use the Autodesk design software. The following discussion, however, will focus mostly on Bentley software solutions due to heavy the investment made by STAs, including INDOT. It will be apparent from the brief overview, that all the software functions required for seamless integration are either commercially available or soon to be, and that INDOT is already well on its way to appropriating the necessary information technology support.

\subsubsection{INDOT's Current Software Alignment}

Recognizing the trends of more infrastructure rehabilitation projects than new-build highway projects and the trend toward seeking stronger project team collaborations, Bentley (http://www.bentley.com/en-US/) has made an expressed commitment to align their software solutions to support the entire project lifecycle, from planning through operations. This vision, no doubt, is a response to the recognition that a BIM-like approach is desirable for non-vertical construction projects. INDOT has heavily invested for over 11 years in the use of design software from Bentley Systems, Inc. The relationship INDOT has with Bentley has enabled the IT department to support its user base to a very high level and create custom workspaces for the many sections within INDOT (i.e. Roadway, Structural, Real Estate, and Survey). MicroStation is the CAD engine for Bentley's specialty design applications.

Bentley owns and supports GEOPAK, InRoads, and MXROAD, alternative software for roadway design, and preferred by different STAs for historical reasons. Among U.S. STAs, only INDOT and the New Hampshire DOT use MXROAD, while GEOPAK is the choice among Mid-American and Mid-Atlantic states and InRoads is more popular with western states and parts of the northeast. Multiple DOT sources state that Bentley is 
responding to its DOT customer base's call for a total solution for the 3D model-based project delivery paradigm, and all indications from their recent product updates are that this understanding is correct. Both InRoads and MXROAD already support digital terrain modeling and also have the functionality for automatic quantity estimation. While MXROAD imports files in the LandXML format, it does not appear to support conversion to LandXML. It is likely, however, that this needed change is not far ahead since InRoads already has the capability.

To support project collaboration, Bentley offers ProjectWise, which facilitates the sharing of information across distributed teams. The software is designed for managing, finding, sharing, and visualizing CAD and geospatial content, project data, and Office documents. Therefore, Bentley has the requisite knowledge regarding the objectives that would be appropriate for CIM.

In 2008, INDOT has deployed ProjectWise and will link all of INDOT's users together in one environment for a more seamless sharing of data regardless of location or function. This deployment is part of the implementation of the V8 XM version of MicroStation and MXROAD V8 XM. The main ProjectWise data server (Oracle) is located in the Indianapolis Central Office. There are six additional caching servers located throughout the state (Laporte, Ft. Wayne, Seymour, Crawfordsville, Greenfield, and Vincennes). INDOT has approximately 120 initial users-design engineers, drafters, surveyors and environmental engineers-in the Central Office and between 60-80 users in the districts. A second round of users, between 300 and 400, will consist of all non-designers such as managers and reviewers. As part of the ProjectWise development INDOT has also created a Sharepoint site (user and a Help Desk and FAQ repository) with the intention of going outside the INDOT firewall to allow for INDOT consultants to post to ProjectWise through the web interface, a development to take place later in 2008. This development will enable sharing of intelligent electronic deliverables with subcontractors to perform detailed design and will facilitate the review process for completed designs. INDOT also plans to deploy the FileNET connector to its Electronics Record Management Service (ERMS) which has a Green Pasture Software (lifecycle document management) front end. This will allow for project archiving directly out of ProjectWise into ERMS. The final step in the development process of ProjectWise will be 
the SDE (software development environment) link to ESRI GIS software. Research has already begun on this step and it will be deployed during the late 2008 - early 2009 timeframe. Thus, INDOT is positioning itself to work collaboratively with both internal and external customers and consultants and laying an effective foundation for realizing the benefits of sharing intelligent EDFs.

There are a few additional products from Bentley such as PowerSurvey and Bentley OnSite that are also to be adopted in the future to help with Surveying and Real Estate units of INDOT. These products are completely interoperable with Bentley GEOPAK, InRoads, and MXROAD design software and integrates with industry-standard formats, field data collection devices, and design platforms and will thus not require a complex conversion process. Database components support the linking of important information to the survey data. It is important to note the seamless sequential transmission of data and information that is enabled by these applications. Survey data collected electronically in the field can be uploaded to the PowerSurvey application to immediately begin creating the topographic drawing that can then be imported to one of Bentley's other applications to complete the design. OnSite is then used during construction for stakeout and inspection to document grades and confirm quantities. A survey of estimating software websites confirms interoperability with quantity estimating and bidding software that might be used by contractors, with the DWG and LandXML formats appearing most often to facilitate the process.

As a final comment, it is worth noting a few more specific capabilities enabled by the Bentley software product line. Michigan DOT (MDOT) uses Bentley's ProjectWise to manage its eProposal process, which distributes intelligent Adobe PDF design files. It is reported that by using this system, MDOT has been able to develop an electronic workflow with effective document flow, eliminating physical hand-offs of hard copy plan sets. In the previous section, it was noted that design review would not require EDFs but that PDFs would be more appropriate. MicroStation V8 XM, users can attach PDF files as a reference to DGN and DWG models to close the loop on design and review cycles. Finally, regarding file security, MicroStation provides users with a complete revision control system by enabling teams to track and view incremental changes and to validate those changes using digital signatures which confirm the status of each design document. 


\subsubsection{Autodesk Compatibility for Consultants}

Autodesk, Inc. (http://www.autodesk.com) has developed its solution to advance CIM in its AutoCAD Civil 3D ${ }^{\circledR} 2009$ product. This software is designed to support a collaborative workflow, providing project team users with access to project design information maintained in a relational database. Designs can be developed beginning with the import of field survey data and 3D intelligent object technology facilitates the creation, management, and analysis of the 3D surface model. An advanced data management capability offers change management, version control, user permissions, and archive control. The source drawing (design file) is accessed as a reference to the source file, protecting it from any editing except by individuals having authorization to access the source to make needed changes. The software supports LandXML import and export, suitable for translation to 3D-MC input formats. AutoCAD Civil 3D ${ }^{\circledR} 2009$ also supports MicroStation V7 and V8 formats (DGN and DWG) which enables designers to still provide designs in the format that most STAs prefer. Therefore, there is no barrier to consultants who prefer to use Civil 3D working seamlessly within INDOT’s PDP as supported by mainly Bentley software.

\subsubsection{Summation Regarding Software Tools}

From the overview of both of the leading providers of software for road design, Bentley and Autodesk, it is apparent that solutions exist to support electronic data and information management for all the stages of survey data collection, design development and review, quantity estimating, and site monitoring and inspection. Numerous options of interoperable hardware and software tools exist for the use of the DOT owner, design consultants, and contractors. The sharing of information is further facilitated by a secure project-based digital information environment, well-equipped with functions to track updates and changes. Only the expense of perhaps adopting new software and the time required for learning how to incorporate the tools into an efficient work flow and training personnel are barriers to a DOT developing a seamless PDP computing solution. INDOT's current trend in adopting the wider range of Bentley products, especially the inclusion of ProjectWise, well aligns the agency to develop the technical capability to implement seamless integration both within INDOT and with design consultant and contractor project partners. Technologically 
speaking, CIM is just as much of a possibility as BIM, perhaps even more so due to the unique owner and project attributes found in the transportation sector of the construction industry.

\subsection{Information from Vendors and Practitioners}

The next phase of the study was aimed to obtain a picture of the state-of-the-art and/or the state-of-the-practice with regard to utilization of EDFs and 3D-MC as they relate to transportation projects. Toward that end, several groups were targeted as sources for information: vendors of GPS-based 3D-MC systems to obtain the most up-to-date description of their commercially available technologies, contractors to balance advertised capabilities with user experience, design consultants and engineering service providers (firms providing 3D design file preparation services to designers and contractors), and select STAs or related practitioner groups to learn from their experiences in facilitating the use of EDFs and 3D-MC on their projects. Information was obtained by interviews (usually phone) and surveys. Since respondents were not required to give opinions about a specific controlled experience facilitated by the Investigators, no approval for study of human subjects was required. The information obtained provided an overview of commercial software options and data and file formats that are encountered in practice and experiences regarding lessons learned from project implementation.

\subsubsection{Technologies for 3D Machine Control}

The first requirement for machine guidance is some sort of land based measurement reference, whether it is using total station, laser, or GPS. For the total station technology, the device, a robotic total station is set up in a desirable location with reference to known 3D reference on or at the project site. For laser or GPS, a base station is set up over a known geo-referenced point. The receivers in the equipment receive a signal from this base station

or are tracked by the robotic total station to get their position in the coordinate system. In the case of the robotic total station and laser systems, the receiver on the roving machine must maintain a direct line of site with the base station(s). GPS receivers obtain signals from both the satellites and the base station, which allows it to correct for errors inherent in the satellite 
signals. Having to correct for this error keeps the accuracy at only the centimeter level, while the robotic total station and laser can obtain much greater accuracy. Some 3D-MC systems make use of a combination of both GPS and laser systems to reach millimeter accuracies. More than simply $3 D$ machine guidance, the systems available today allow for documenting the day's work from the onboard computer, although to do so requires that the area worked be traversed again with the system set in the appropriate mode for collecting the surface data and saving it to a disk for transfer to an office computer. This information can be transmitted back to the engineering office to generate reports of productivity and estimates of the remaining work (Navon and Shpatnitsky 2005).

Currently, there are three main manufacturers of machine guidance equipment, Topcon Positioning Systems, Inc., Trimble Navigation, Ltd., and Leica Geosystems. All have been involved in the land surveying industry, and thoroughly understand the requirements for accuracy in positioning. Having successfully developed their product lines, they have also begun working with construction equipment manufactures on making the machine guidance tools listed optional equipment available from the factory. This tactic is aimed at increasing the speed of adoption of the technology among construction firms, as they will not need to have their current equipment out of service for retrofitting.

Caterpillar, Inc. worked with Trimble, in one of the earliest partnerships which has established them as the market leader, to create the Computer Aided Earthmoving System (CAES). Their partnership then produced systems for the construction industry. Trimble has also formed partnerships with John Deere, Case, and Volvo. Topcon is now working with John Deere and Volvo to provide OEM machine control. Leica, who carved out a name for having superior survey and photogrammetric equipment, is a late comer to machine control for construction, having staked its initial claim in precision farming for the agricultural industry, and is working with Case on providing OEM machine control.

As the accuracy of the GPS technology has improved, more construction companies have purchased systems. A case of early adoption of the technology was by the McAninch Corporation of Des Moines, Iowa, which served as a beta tester in 1999 for Trimble. Caterpillar and geotechnical engineering faculty from Iowa State University were also involved. The company founder serves on the board for the joint venture technology development company, Caterpillar Trimble Control Technologies. Since 1999, sales for all 
three of the GPS machine control vendors have continued to increase in the U.S. market, and interoperability in not only the software, but also the firmware is being addressed (Fiscor 2000).

First used primarily for rough grading, where its centimeter accuracy could best be taken advantage of, systems are now capable of providing satisfactory accuracies for finish grading where there are tighter tolerances. As the accuracy has improved, GPS-based machine control is now finding its way to asphalt paving machines, allowing contractors to produce smoother driving surfaces. This development has allowed construction firms to pave smoother driving surfaces. Such systems are more costly, though, as they require a laser system to be used in conjunction with the GPS setup. The next three sections provide and overview of the current system options and the capabilities they afford.

\subsubsection{Trimble Navigation}

As mentioned earlier, Trimble (http://www.trimble.com/) has the lion's share of the market due to the success of their early partnership with Caterpillar. Trimble's original 3D-MC system for construction, SiteVision GPS, has been succeeded by Trimble GCS900. The system uses GPS, GPS and laser, or total station technology to accurately position blade or bucket in real time, and is designed for use on excavators, dozers, scrapers, motor graders, and compactors. Single and dual GPS antennae solutions are available. In-cab indicator light bars which guide the operator are still standard features. Both indicate and automatic modes are available. Systems and blade control accuracies are published by Trimble as follows:

- Trimble MS980/MS990 Smart GPS Antenna - blade control to 20-30 mm (0.1 ft)

- Trimble SPS930 or SPS 730 Universal Total Station - blade control to 2-5 mm (0.007 to $0.016 \mathrm{ft}$ )

- Trimble GPS with Laser Augmentation - blade control to 3-6 mm (0.01 to $0.02 \mathrm{ft}$ ) Regarding the Trimble CCS900 Compaction Control System, in addition to utilizing the GCS900 Grade Control System software, the system simultaneously collects compaction data and checks grade accuracy in real time. The system displays, maps, and documents 
compaction measurements on-machine, a valuable feature that facilitates satisfying project documentation deliverables.

\subsubsection{Topcon Positioning Systems}

Possessing the second largest share of the construction industry 3D-MC market, Topcon (http://www.topconpositioning.com/) has capitalized on its extensive history in serving the construction surveying market. 3D-MC systems from Topcon come in indicate or automatic control versions, and they have a wider number of system alternatives overall as follows:

- 3D-Millimeter GPS (RTK GPS + laser) for multiple dozers or motor graders

- 3D GPS (RTK GPS + GLONASS tracking) for multiple dozers or motor graders

- 3D LPS (total station combined with laser communication) for single dozers or motor graders

- 3Di (-GPS) indicate only for dozers and scrapers

Published accuracies are $0.1 \mathrm{ft}$ with RTK GPS and $0.02 \mathrm{ft}$ with laser added to the GPS (mmGPS). For Topcon customers, the mmGPS is desirable because it comes at about half the cost of a robotic total station system and can control multiple rovers while the total station can control only one at a time. Maximum working area is $33 \mathrm{ft}$ high by $1968 \mathrm{ft}$ diameter (10 $\mathrm{m}$ by $600 \mathrm{~m}$ ), but linking transmitters can increase the working volume.

\subsubsection{Leica Geosystems}

Although they also have a strong historical presence in the global construction market, Leica (http://www.leica-geosystems.com/) came entered the 3D-MC market based on a transfer of it experience gained in machine control for farming equipment. To achieve the most extensive GPS satellite coverage, Leica combines signals from the United States GPS constellation with the Russian GLONASS in their GNSS/GPS systems to provide 3D control for dozers, graders, and excavators. Leica refers to their robotic total station radio surveying/tracking as TPS. There are two specific systems available from Leica developed for earthmoving operations: 
- DigSmart 3D (GNSS) for excavators, delivering cm-level accuracy with indicate mode only

- GradeSmart 3D (GNSS or TPS) for dozers and motor graders with indicate or automatic modes

While the Leica website and product brochures do not report actual numbers for accuracy, the company does market GradeSmart 3D as being capable of meeting the tolerance requirements of road construction. In describing the performance of an earlier version of the Leica system — the Dozer 2000 — at the San Miguel lignite mine, Fiscor (2000) reported accuracies for finish grade work within +/-2 inches. The basic GradeSmart system, which is laser based, can be upgraded to 3D with either GNSS or a robotic total station. Leica PaveSmart 3D is another product available for asphalt road pavers (total station), milling machines (total station or GNSS), mainline slipformers (total stations), trimmers, curb and gutter slipformers (GPS base stations).

\subsubsection{Sequence of Tasks for Using 3D-MC}

The general procedure for using 3D-MC systems is the same regardless of vendor. Following is that described by Brown (2001) for Trimble's original 3D-MC system for dozers and motor graders:

1. Licensed surveyor establishes control references for the site (for northing, easting and elevation- $x, y$, and $z$ coordinates)

2. Set up and calibrate base station (calibration is site-specific and saved as siteconfiguration file)

3. Create DTM from engineer's project design

4. Convert DTM to Trimble [SiteVision] format

5. Transfer Trimble DTM to flash card to transfer to onboard computer

In order for EDFs to be used in machine guidance, the site plans must be created or redone as a DTM. These are then converted for use in the 3D-MC equipment via proprietary software which each vendor has developed. This software translates the DTM into a vendorspecific format which the respective 3D-MC system can utilize, and it also automatically 
checks the plan for obvious errors in the construction of the model surface which would prevent the equipment from performing properly. Contractors may choose to perform the file conversion (from 2D to 3D or DTM to vendor format) in house, or they can have it done by an external engineering firm which specializes in translating the model. These service providers are typically firms which have traditionally provided engineering surveying services and therefore are proficient in dealing with coordinate transformation issues that arise in file preparation.

One infrastructure change that is facilitating the process of establishing site control in some geographic areas is the establishment of continuously operating reference stations (CORS) networks. Each CORS site provides GPS carrier phase and code range measurements in support of three-dimensional positioning activities throughout the covered region. Projects located in areas covered by a CORS network do not require setting up a base station for the project that utilizes GPS for project control, including rovers. The specific technology needed for 3D-MC systems to operate from a CORS network has not yet reached the commercial market although this integration gap currently is receiving attention from technology developers. The INDOT Office of Aerial Engineering is currently in the process

of putting a CORS network in place for Indiana with the end of 2008 as a target for having the necessary equipment installed and operating. This decision results from a commitment to maximize the benefits of GPS technology for land surveying and is further motivation for finding a way to facilitate the regular use of 3D-MC in construction when that capability becomes accessible to contractors. Once 3D-MC systems are able to connect to CORS networks, the investment cost for the contractor who purchases a new CORS-ready 3D-MC system for the project will be less than what is currently required. As a practical economic matter, however, it should be recognized that there may still be contractors who own unmodified older 3D-MC technology and who will still need to set up a base station.

\subsubsection{3D-MC System Costs}

There is also a question of cost of the GPS system compared to traditional stake grading for laser machine guidance. According to one source, laser systems generally cost about $\$ 20,000-50,000$ for a rotating laser and receiver. By comparison, GPS systems 
generally start at $\$ 80,000$ for a base station and one machine setup with an automated control

system. As noted above, the presence of a statewide CORS network would further reduce the purchase cost as the purchase of a base station is expected to become unnecessary.

Construction firms which were early adapters of the technology say that they quickly recoup the price of the equipment in cost savings. Guinn Construction Co. in California estimates that their payback on the GPS equipment is under two years, but for firms which do a higher volume of work, that time could be a lot shorter (Brown 2001) According to Mark Nichols, who was the general manager of the joint project between Caterpillar and Trimble, using 3D guidance and machine control technology would take anywhere between 15 and $30 \%$ out of the cost of earthmoving and preparation phases (Zeyher 2002). What used to be an automatic $\$ 100,000$ investment just to equip one machine with GPS-based control is now much more accessible to smaller contractors and there is arguably adequate anecdotal evidence that the investment cost is quickly recovered on the first few projects.

\subsubsection{3D-MC Alternatives Summation}

Based upon the interest of the Indiana Construction Association (ICA), which is dialoguing with INDOT regarding implementation of 3D-MC technology and supporting specifications for their projects, it appears that a number of contractors either have made some investment in 3D-MC or expect to either initiate or add to such an investment in the near future. As noted above regarding the cost, the technology is certainly more accessible today to a wider range of contractors, with respect to size, than it was at the turn of the century. While all three of the market-leading commercial systems appear to be capable of delivering the accuracy and tolerance performance typically required, at least for rough grading, it appears that more contractors in the Indiana region who have invested in 3D-MC have opted for either the Trimble or Topcon systems. The Investigators believe that, perhaps among other things, the confident reporting, and corroborations from trade journal reviews, of expected accuracies contributes to greater interest from the potential contractor customer. 


\subsubsection{STAs' Use of Electronic Design Files}

Whether the designer (whether within the STA or a consultant) provides a 2D or 3D EDF to facilitate the CIM process, there are important issues to be addressed that all STAs recognize but have addressed in various ways. From an overview of literature and discussions with STA personnel, noted chief concerns are the 1) tasks for which EDFs are to be made available and the standards for preparing and submitting EDFs; 2) security, i.e., protection from tampering, of the design files; 3) assurance that all parties are working from the correct version of the design files, i.e., that multiple versions are not being used simultaneously by different parties, since electronic distribution is not as easily controlled as doing it by paper; and 4) additional cost of meeting new standards for design preparation. The overall objectives are to enhance efficiency of information exchange and thus the collaborations between project parties and to also improve the quality of the both the design and construction processes.

In Section 5.2, the INDOT PDP was reviewed and tasks that draw upon access to the design files in some form were highlighted, thus already addressing one half of the first concern noted above. By having ready access to some electronic form of the design files, it is accepted that the state can realize improvements to the road design and construction process. Especially when consultants produce the design, the state can be kept in the loop as the design progresses, identifying problems and providing more immediate feedback. It can be suggested that the principal role and scope of similar information technology for the construction phase should be the support of predictions of the anticipated performance of the design of a project's scope, schedule, and organization (Fischer and Kunz 2004).

Aside from the noted advantages to the STA for project planning and design, another advantage of using IT in project development is contractor ease. For a large project, the use of EDFs would aid in the use of multiple construction firms and the ability to easily share design information between multiple firms. However, there are many advantages which can be realized regardless of the size of the project. Having designs in an easily shared electronic format allows for the ability of the contractor to more easily and accurately estimate costs for earthwork, paving, and other aspects of the project. Time can also be saved if a contractor can avoid spending the time and expense of digitizing paper-based two-dimensional plots just so they can utilize 3D-MC. Finally, as-builts are more readily created when the EDF is 
available to the contractor. A thorough exploration of the all the advantages to the contractor is beyond the scope of this study, but may be worthy of future study.

It is worth noting that design-build, which involves the partnership of a general contractor and a design firm, is an increasingly popular project delivery method that may most fully exploit collaborative practices such as those facilitated by the CIM concept. The construction contractor is involved in the design process from the beginning and can provide helpful insights on construction materials and methods that can make the design more efficient and less costly to construct. For states which complete design in-house, a publicprivate partnership can provide equivalent benefits. Another factor to consider is that partnerships of this type are generally entered into by larger firms more likely to already have sophisticated computing resources and 3D-MC technology.

The following sections discuss further the issues raised concerning STAs' use of EDFs in project delivery and highlight the solutions either implemented or being explored by STAs. The availability of specific technology options are noted for consideration where appropriate.

\subsubsection{Preparing, Submitting, and Sharing EDFs}

There are four distinct types of decisions for STAs to make regarding the handling of electronic versions of the design files. The first is what the state does to regulate or encourage the use of design files. The state must next decide how the files are to be submitted or provided. This an area in which many options are available. The state must also regulate when and how the files should be made available to those outside the engineering firm and the STA. There are important concerns here with regard to maintaining a level playing field for all contractors. The final decision concerns whether and how to have the EDFs utilized in machine guidance on a project. Although the desire to facilitate 3D-MC is a major driver toward adopting procedures for obtaining the EDF, the growing pressure to achieve more efficient communication and collaboration and interest in VDC technologies are reason enough for an STA to move in this direction. To learn how STAs are addressing the first three of these questions, the Investigators conducted a review of information posted on STA websites and gathered additional information from trade journal documentation and 
personal interviews (usually by phone). The utilization of EDFs for machine guidance is discussed in a separate section.

All STAs which utilize outside design consultants provide base files to be used for their designs. Like INDOT, a large majority of states have chosen MicroStation, by Bentley, as their software package of choice for producing the guide files and require submitted files follow this format. Many also require add-in programs, such as GEOPAK, InRoads, or MXROAD for design geometry and terrain models, and the BIM-inspired ProjectWise is now being adopted for server management. There is also a growing interest in utilizing the open source file format know as LandXML, mentioned earlier, to more easily share files, as it does not require a specific software suite. Since the competing design suites (MicroStation and AutoCAD) can each read the other's file formats, using LandXML is not seen as a requirement, but it does allow for an STA to not appear to force a design firm to choose one software suite over another.

A major advantage of digital plans is the ability for multiple people or firms to be involved in the process. Preliminary plans may be quickly transmitted to the state for initial reviews and comments, and can be utilized in later steps such as right-of-way and utility reviews. For example, for Step 7 in the INDOT PDP, the ROW alignment could be distributed electronically to the utilities, who could lay the plans over their own layers. The alignment could also be imported into a GIS, which could be used to sort a contact list of property owners along the proposed ROW. This will save time and resources, and each department has access to the plans without multiple sheets having to be copied and distributed. Such sharing of digital plans is particularly helpful in a highly collaborative contractual relationship such as design-build or public-private partnership.

File formats and transmission of design files are problems which typically need to be solved by the STA in accordance with their technical and staff resources and their tolerance for liability. A review of state practices as described on their Web sites revealed that a majority have standards for what format (if any) files must be in when submitted to the agency, as well as the method of submittal. A summary tabulation of the information found in this review is included in the Appendix (Section 8). The details in the table range from specifics of file format, submittal guidelines, and digital signing of the files, to allowing only paper copies of the design, although the latter is becoming rare. 
Transferring plans over the internet introduces some additional risks, with the advantage of reduced time delays. While reviewing plans either by hard copy or even with the use of manually transferred digital media can take several days, utilizing file transfer protocol (FTP) distribution can allow an STA to receive, review, and comment on plans all in one day. The implication of this is decreased time for the planning process, and better communication between the STA and the design firm. Rapid turnaround of designs will also improve the design-build process.

A simple in-house solution for design submittal that requires some work from the state's IT unit is to work with a password protected FTP site. Each design firm is given a unique password to be used on a section of the state's drive system. The design engineer can then utilize the file transfer protocol to submit their files to the STA. Since the designer and state agency are the only groups with access, the files should remain secure. Logs can be created showing who has accessed the folder, when they did, and what activity was performed. Alternatively, it would be possible for the designer to send the files to the STA via compact disc. This option, however, does have some drawbacks, including a limit on file size, the chance for data to become corrupt during the burn process, and the potential for delay in transmission.

Commercial options also contain features for handling submittal. Michigan (MDOT) conducts e-bidding, utilizing only PDF (proposals) or TIFF (bidding) versions of the conventional 2D design model. They accomplish this through ProjectWise instead of an inhouse solution. ProjectWise was documented as an effective tool for managing project document sharing for Kentucky as it was used to facilitate collaboration between multiple agencies and design firms by providing shared access to about 20,000 files for reconstruction of the Kennedy Interchange (junction of I-65, I-64, and I-71) in downtown Louisville (Bentley Systems, Inc. 2008).

\subsubsection{File Security}

The summary of concerns among the methods of transmittal of plans comes down to the safety and security of a set of plans, and how the designer or STA can be sure that the plans have not been somehow corrupted. This can be an alteration of the file either intentionally or 
unintentionally by some party, or through some error in the sending and storing of bits of data. While files are certainly less likely to have errors of this type than they were, say 10 years ago, problems can still occur.

Optical media, as either CD or DVD form, offer the more secure method of transfer. Data is transferred directly from the designer's hard drive to the disk, and sent to the necessary parties. Other than the slight chance of the data not being burned properly to the disk, which can be checked immediately after the transfer, there is little else which can happen to the data. This method is used by many states, such as Massachusetts and Missouri, for the final design. Typically, a hard copy of the design accompanies the disk, upon which the engineer can affix their seal, as is the practice in Montana. In such instances, the paper copy is maintained as the official design document of record.

A number of states have been working on a solution for safely moving design files across the internet. One possibility is for the state IT department to create project folders that are accessible only by those who have the correct username and password credentials. This limits the ability to upload, download, or view the files by those who are given proper authority. Georgia has set up a secure ftp system for their utility companies to indicate the location of their facilities on construction projects. Arizona has allowed for FTP uploading of files since 2005.

Florida has developed a proprietary system for submitting design files. Engineering firms can download a program named Professional Electronic Data Delivery System developed by ModernTech. After they have completed the project, the designer loads their files into this system. The package then uses an algorithm based on the design files to build a bit check file. If any of the design files are changed, they will not match the bit check, and the user will know that the files are corrupt.

Another method that has been developed is to digitally sign the files using a third party to ensure the validity of the seals. A digital signature is an electronic means to authenticate the identity of the sender of a message or the signer of a document and possibly to ensure the original content of a message or document has not been changed during transmission. Adobe has a system to digitally sign PDFs, and both Bentley (MicroStation Digital Security) and Autodesk (Digital Signature Extension) support digital signatures for design files created with their software. An important development that can completely 
eliminate the need for the paper copy of the design file is the ability to digitally sign an engineer's seal which has been affixed to the design files. The Banjo plug-in by LineType Software, Inc. (http://www.linetype.com), for Adobe Acrobat, allows such sealing of the PDF versions of design files. Electronic file security providers not uniquely aligned to the construction industry, such as Verisign, Inc., also exist to provide electronic security solutions for Internet transactions.

\subsubsection{Version Control}

Collaborating by means of sharing EDFs brings with it the very specific security- and liability-related issue of revision tracking. There is a practical need to ensure the correct version is being referenced during design development as well as during construction when changes are occurring or grades and other dimensions are being confirmed. An advantage of soft copy design is that it can be easily and quickly delivered to many people for review, adjustment, and comment. However, if many changes are made in a brief period of time by many people, there is the increased chance that a wrong version of the plans is used as the official contract document. The design engineer, STA, and contractor must be able to identify the final set of drawings, and ensure that they cannot easily be altered. Many states accomplish this by accepting only PDF versions of the plans. This can address the security of the design files, but eliminates any advantages gained from automated extraction and use of the design data. If EDFs are used during planning and design, the STA will have to work with the design firms to create a solid data flow, possibly having all revisions or suggestions going to the lead designer or PE in charge of the project, with this person accepting or rejecting any proposed changes and altering the main document.

STAs may also opt to not use the EDFs during the design phase, instead opting to leave the handling of the files between the engineering and construction firms. They can also utilize the EDF solely for the purposes of their review, and have the design firm provide the files directly to the successful bidding firm. By this option the STA protects itself from any liability for transmitting an incorrect version of the design. There is also the option of utilizing a release form if the state works as a go between, as is done in Delaware, but not currently practiced by INDOT. This issue is discussed more in the liability section (5.3.6). 
With respect to commercially available options, both Bentley and Autodesk offer some provision for version tracking. ProjectWise has functions for versioning old files (Master and Reference) when a new version is established. AutoCAD Civil 3D ${ }^{\circledR} 2009$ has both change management and version control functions. The source drawing (design file) is accessed as a reference to the source file, protecting it from any editing except by individuals having authorization to access the source to make needed changes.

\subsubsection{Savings and Costs of Utilizing 3D-MC and Providing EDFs}

The work plan for this study included an effort to identify costs, and although not clearly stipulated at the time, it was understood that these costs should be from the perspective of the STA, i.e., the net cost to the STA to facilitate the use of 3D-MC on its projects. Such information for owners was not found in the literature, and even information published regarding the contractor's costs consisted of quotes of isolated figures and not thorough analysis. Table 1 presents the typical manner in which cost savings are reported in the literature. Even where direct technology acquisition costs can be determined, extrapolating the percentage that would be passed on to the owner in the contractor's bid would be highly speculative. Furthermore, the new costs associated with enhanced attention to design would be incurred either in-house by the STA or passed to them by either the design consultant(s) or the contractor. The determination of new costs for design may be quite variable and depends heavily upon to whom and how the responsibility for creation and sharing of the design is specified. In fact, a project manager for Minnesota DOT has been quoted as saying that cost-

savings won't be seen for several years until the industry gets used to automation (Hampton 2005). This assessment still applies to total STA program savings since even the lead adopting STAs are still either in the early implementation phases for their new specifications or are still conducting pilot projects. Although projections might be developed, data is still too limited for confident solid benchmarking. 
Table 1 Typical Examples of Benefits reported by Contractors from Utilizing 3D-MC

\begin{tabular}{|c|c|c|c|}
\hline Source & Project Type/Description & System Utilized & Savings Noted \\
\hline Brown (2001) & $\begin{array}{l}\text { Landfill expansion on steep } \\
\text { irregular terrain calling for a total } \\
\text { of } 1 \text { million cubic yards of } \\
\text { excavation, } 500,000 \text { cubic yards } \\
\text { of which was stockpiled. Two } \\
\text { equipped dozers supporting a } \\
\text { fleet of } 16 \text { push-pull scrapers }\end{array}$ & Trimble SiteVision & $\begin{array}{l}\text { - } \$ 1,000 \text { in staking materials on the } 1500 \text {-ft-long by } \\
\text { 250-ft-high buttress } \\
\text { - Several thousand dollars from } 2 \text { grade checkers for a } \\
\text { month to } 1 \text { grade checker for } 2 \text { weeks } \\
\text { - } 50 \% \text { of outside surveying cost }\end{array}$ \\
\hline Fiscor (2000) & Lignite mine & Leica Dozer 2000 & $\begin{array}{l}\text { - Up to } \$ 200,000 \text { annually by eliminating survey } \\
\text { staking, reducing rehandling, and improving dragline } \\
\text { bench-height control } \\
\text { - Up to } \$ 56,000 \text { projected per dozer for a } 5 \% \\
\text { reduction in rehandling from overcutting } \\
\text { - Up to } \$ 72,000 \text { per machine by reducing dragline } \\
\text { rehandling by } 3 \% \text {. } \\
\text { - Payback expected in less than } 2 \text { years } \\
\text { - Conservative estimate of } 40 \% \text { return on investment }\end{array}$ \\
\hline Brown (2001) & $\begin{array}{l}\text { Airport access road, } 1 \text { million } \\
\text { cubic yards of excavation, } \\
700,000 \text { cubic yards, of which } \\
\text { were used onsite to meet fill } \\
\text { requirements; } \\
\text { both cuts and fills up to } 60 \text { feet } \\
\text { deep }\end{array}$ & $\begin{array}{l}\text { Topcon 3Di-GPS+ } \\
\text { and 3D-GPS+ }\end{array}$ & $\begin{array}{l}\text { - }>60 \% \text { reduction in direct labor costs for grading and } \\
\text { grading monitoring work } \\
\text { - Doubled grading production for both rough and fine } \\
\text { grading } \\
\text { - Elimination of } 10-20 \text { stakes per } 500 \text { feet }\end{array}$ \\
\hline
\end{tabular}


The most informative example of reported cost savings was made available online (http://www.aashtotig.org) from the American Association of State Highway Officials (AASHTO) Technology Implementation Group (TIG) Lead States Team on Automated Machine Guidance. A Tennessee based contractor, Jones Bros., Inc., reported the cost savings comparisons as presented in Table 2 as part of a PowerPoint presentation. These benefits were apparently achieved by Jones Bros. in the construction phase over a number of STA projects, mostly in Tennessee, but also one or two in Florida, Texas, Virginia, and West Virginia. The presenter, Bret Alsobrooks, further reported a 30\% improvement in equipment utilization. In some cases, the magnitudes of savings imply ample benefits for the contracting community to improve profitability and yet pass on some cost savings to the STA through lower bids.

In addition to the benefits presented in Tables 1 and 2, the Investigators also note in Table 3 benefits reported by personnel from transportation project experiences in Florida and New York. The numbers from New York apply to 8 projects conducted during summer, 2008. Possible cost savings corresponding to such results as these might be compared to cost increases incurred by facilitating access to the EDFs for the utilization of 3D-MC.

Table 2 Gains Presented from Experience of One Tennessee Contractor over Numerous Projects (presentation by Bret Alsobrooks, Jones Bros., Inc., Mt. Juliet, Tennessee to AASHTO TIG; http://www.aashtotig.org)

\begin{tabular}{|l|l|l|}
\hline GPS Technology & Compared With & Estimated Savings \\
\hline Grade Checking & Manual method & Up to 66\% \\
\hline $\begin{array}{l}\text { Reduction or elimination } \\
\text { of stakes }\end{array}$ & Using stakes & Up to 85\% \\
\hline $\begin{array}{l}\text { Improved material } \\
\text { yields/select } \\
\text { fills/undercutting }\end{array}$ & $\begin{array}{l}\text { Overruns using manual } \\
\text { methods }\end{array}$ & $3 \%$ to 6\% in volume \\
\hline $\begin{array}{l}\text { Un-interrupted earth } \\
\text { moving production under } \\
\text { any weather conditions } \\
\text { (24/7) }\end{array}$ & $\begin{array}{l}\text { Daytime / fine weather } \\
\text { operation only/night work }\end{array}$ & $30 \%$ to 50\% \\
\hline $\begin{array}{l}\text { RTK, robotic stakeout } \\
\text { Traditional survey stakeout }\end{array}$ & $\begin{array}{l}\text { More than } 100 \% \text { in speed } \\
\text { and 66\% in staffing }\end{array}$ \\
\hline
\end{tabular}


Table 3 Project Benefits for Construction Cited During Interviews

\begin{tabular}{|l|l|l|l|}
\hline Source & $\begin{array}{l}\text { Project } \\
\text { Type/Description }\end{array}$ & $\begin{array}{l}\text { System } \\
\text { Utilized }\end{array}$ & Savings Noted \\
\hline $\begin{array}{l}\text { Interview, } \\
\text { Kiewit Southern } \\
\text { (2008) }\end{array}$ & $\begin{array}{l}\text { 12.5 mile widening } \\
\text { of I-95; 75\% of } \\
\text { machines equipped } \\
\text { with 3D-MC }\end{array}$ & $\begin{array}{l}\text { Primarily } \\
\text { Trimble }\end{array}$ & $\begin{array}{l}\text { Approximately 8-month project } \\
\text { schedule reduction projected }\end{array}$ \\
\hline $\begin{array}{l}\text { Interview, New } \\
\text { York State DOT } \\
\text { (2008) }\end{array}$ & $\begin{array}{l}\text { 8 projects during } \\
\text { Summer, 2007 }\end{array}$ & Not cited & $\begin{array}{l}\text { Major increases in productivity by as } \\
\text { much as 40-50\% noted primarily for } \\
\text { the placement, grading and removal } \\
\text { of granular materials. }\end{array}$ \\
\hline
\end{tabular}

Turning to the question of costs related to the extra attention given to producing the 3D design, an STA, when contracting for design services, must consider whether to pay the consultant for this service or to incur the hidden cost of the contractor expending the effort to create the 3D design file. The latter should be considered carefully for all its implications. For example, in 2005, one technician employed by a contractor firm which routinely prepared their own 3D files from 2D EDFs stated that for a 10-mile road project, the conversion could take six weeks or more to process before earthmoving machines could be mobilized (Hampton 2005). A lessons learned document from the Michigan Department of Transportation (see Appendix) notes a citation that contractors are paying about $\$ 10,000$ per lane-mile to acquire their own DTM generated from the paper plans. In the past, there was not as much concern regarding the use of layers and parts of a design, such as the roadbed and drainage sections, matching as they would eventually be reduced to a two-dimensional plan printed on paper. To facilitate 3D-MC, the designer or the entity who redrafts a 2D design will need to be sure that all surfaces match in three dimensions. Not a simple push-ofa-button conversion, the process of converting the model to a proprietary 3D-MC format may take several weeks to complete. Contractors are thus motivated to see that this work is done as part of the front-end process.

The cost savings achieved during construction may only be realized as design firms adapt to the higher design objectives required by 3D-MC. Engineering design firms are challenged by 3D-MC requirements to give considerably more attention to detail than they are accustomed to giving (Hampton 2005). In a survey of several firms who have done 
design work for INDOT, the Investigators found that firms are already utilizing file formats which can be utilized by machine guidance software. Those not creating suitable files were using design software packages which were capable. There could be a cost in training design personnel to be sure that the files are able to be used with machine guidance.

This necessary extra care in drafting, however, once part of the designer's routine, is not expected to add much to the cost (Hampton 2005) of design. CADD design software such as Bentley's MicroStation can warn of a discontinuity in the surface. As part of using the machine control equipment, the purchaser is required to use proprietary software to prepare the file for use with the guidance equipment. This software also has safeguards to warn the user of any errors in the surface, and according to users (engineering service providers and contractors), this rarely happens so long as the original surface is error free.

In his presentation titled "Business Advantages of Using 3D Technologies" given at the 2006 International Highway Engineering Exchange Program Conference, Daniel Streett of the New York State Department of Transportation (NYSDOT), cited an estimated return on investment savings of 4-6\% of total project costs for utilizing the 3D design model. This estimate should be taken as a projection based upon a thorough review of the extent of usage expected for the 3D EDF in the NYSDOT program. The projection does not refer only to utilization for 3D-MC, but for all functions throughout the PDP.

\subsubsection{Overview of STA Progress Toward 3D-MC Implementation}

Regarding the decision of whether and how to have the EDFs utilized in machine guidance on a project, states have to decide to what extent they will govern the use of machine guidance in their construction projects. Options run from allowing the market (i.e., the contracting firms) to control how the technology is used to strictly regulating its use according to standard specifications. Regardless of the course of action, numerous states have realized that there needs to be some involvement on their part and are at some stage of sorting out their approach.

Members of the study advisory committee (SAC) for this study put forth the desire for INDOT to conduct a pilot project before instituting any requirements for designers and contractors. The Investigators found that several states have either completed or are in the 
process of executing such pilot projects. Some have already implemented new procedures to facilitate 3D-MC and the associated submission and sharing of EDFs. While the Investigators learned of instances of 3D-MC being used on transportation projects solely due to the initiative of the contractor, this study has focused on identifying true pilot project cases, i.e., examples where the STA has actively facilitated the use of 3D-MC, or documented changes in the STA's specifications and practice in order to facilitate 3D-MC. From the cases discovered, it is clear that there is still diversity among STAs regarding the course for how EDFs can be efficiently and safely handled, but the industry's transition to 3D-MC is well on its way.

What is clear is that both STAs and contractors are convinced that 3D-MC technologies have true potential to save time and money. It is typical for states to have some form of task force or joint-committee that is addressing the use of 3D-MC and promoting pilot projects for the purpose of testing trial specifications for its use. At the national level, the Technology Implementation Group (TIG) of the American Association of State Highway Transportation Officials (AASHTO) has organized a Lead States Team, consisting of representation from several STAs, the Federal Highway Administration, private contractors, and developers, which is working to accumulate and disseminate knowledge and best practices regarding AMG (AASHTO 2007). As indicated above, the TIG Web site (http://www.aashtotig.org) offers a few documents of interest. In the following sections, summaries of some current STA utilization of 3D-MC are presented as determined from trade literature, phone interviews, STA Web site postings, and other internal documents made available by some of the Lead States Team members.

\subsubsection{Minnesota Department of Transportation}

Minnesota DOT $(\mathrm{Mn} / \mathrm{DOT})$ is regarded as the first STA to formally test the 3D-MC, specifically GPS-based, technology. Mn/DOT elected to try the technology in the noncritical area of roadside retention ponds along a state highway project. After this successful start, they have developed a complete division within the STA to deal with technological issues. In further studying the feasibility of its use, Minnesota discovered there were some areas of the state that GPS control was not sufficient enough to warrant use of the 
technology. They have opted to designate what projects are suitable for GPS machine guidance, leaving the decision of using it to the contractors. The state has a checklist posted online [see Appendix 8.1] to follow when deciding if a project is eligible for machine control, and requires a review of the project if a consultant designs the project.

\subsubsection{Pennsylvania Department of Transportation (PennDOT)}

While developing specifications for using GPS technology, including automated machine control for rough and fine grading, the Pennsylvania Department of Transportation (PennDOT) drew in part upon its concurrent experience with the use of the technology on the 14-mile-long DuBois-Jefferson County Regional Airport Access Road project. The contractor utilized dozers and graders equipped with indicate and automatic control systems. Several weeks gain in project time savings were attributed, in part, to a more rapid grading operation enabled by the GPS-based machine guidance. The project involved one million cubic yards of excavation, 700,000 cubic yards, of which were used onsite to meet fill requirements, and both cuts and fills were up to 60 feet deep. Minimal traditional surveying and GPS surveying were both employed in order to confirm the accuracy of the GPS-based grading. Originally specified for stakes placed at 25-foot intervals for subgrade and 50-foot intervals for cuts and fills, the project benefited from the elimination of 10-20 stakes per 500 feet. To facilitate future use of the technology, PennDOT has formulated an addendum to be inserted into PennDOT Publication 408, Section 210 Specifications.

\subsubsection{Kentucky Department of Transportation}

While the Investigators did not obtain details of specific pilot projects from the Kentucky Department of Highways $(\mathrm{KDOH})$, it is worth noting that, in response to contractors' requests, $\mathrm{KDOH}$ has opted since spring 2006 to require submission of certain EDFs along with the final contract plans, which they make available for sale to bidders by DVD/CD to accompany the printed full-size and half-size plan sets. First generation mylars or reproductions thereof, however, remain the legally binding set of plans. Since initiating this policy, $\mathrm{KDOH}$ has continued to monitor and modify this policy for improvements. 


\subsubsection{Florida Department of Transportation}

Florida has already established a method for designers to submit files using available software. Near Coral Gables, FL, Kiewit Southern is working on a widening project along a 12.5 mile stretch of Interstate 95. This is a design-build project with HNTB as the design firm. For the project, $75 \%$ of the equipment in use is 3D-MC-equipped. A manager overseeing the project estimates that the use of machine guidance may cut up to 8 months off of the project.

\subsubsection{Iowa Department of Transportation}

In January 2006, Iowa Department of Transportation (DOT) took the step of requiring the use of GPS machine control in the construction of roadway embankments (Iowa Development Specification DS-01073), but by March 2007 altered the wording to allow contractors to use machine control (DS-01077). This was further adjusted in September by DS-1103, which removed the STA as a middle step of the documentation process, and allowed for the contractor to receive the documents directly from the consultant, and placed responsibility for accuracy and file conversion on the contractor.

\subsubsection{Georgia Department of Transportation}

Georgia Department of Transportation (GDOT) includes the use of 3D-MC in their specifications. As a matter of practice, GDOT makes decisions on using machine guidance during the initial scoping of the project. GDOT will review and issue EDFs in their standard format. Supplemental specifications for subgrade construction describe required generic components for GPS-based 3D-MC systems that are available from any of the three leading vendor systems. When GPS-controlled equipment is used by the Contractor, a minimum staking interval of $300 \mathrm{ft}$ (English unit projects) or $100 \mathrm{~m}$ (SI projects) is still required. Specifications allow the Engineer [of record] to direct the Contractor to use laser-controlled equipment, with some requirements on their setup, if the Contractor fails to meet specified tolerances utilizing GPS-controlled equipment. The Engineer also has the stipulated authority to approve the omission or inclusion of a fine grading machine for subgrade and subbase construction. 


\subsubsection{Michigan Department of Transportation (MDOT)}

MDOT conducted a pilot project in summer 2007 requiring machine control and received five bidders and the one awarded the project had to purchase a 3D-MC system for the project. MDOT took responsibility for providing the design and hired Bentley Systems, Inc. to build the model. Although MDOT experienced various problems on the project, the problems were of such a nature that MDOT was not discouraged from planning a second pilot project for summer 2008. Entitled the MACH1 project, MDOT intends the second pilot project to focus on testing machine controlled grading and the use of Bentley Onsite software (for construction inspection). As a step in planning for the new pilot project a document of lessons learned was composed from their past pilot project and also gleaned from other states and is included here in the Appendix. The project involves constructing a modified 0.6-mile boulevard section on US-127 Business Route south of Mt. Pleasant.

MDOT’s plan for MACH1 (March 2007 through March 2010) includes Consultant services to assist MDOT with Bentley software configuration (GEOPAK criteria) to produce 3D terrain models; training for MDOT GEOPAK/CAD support staff to create DTMs, design archives, and train others in the future; training for Construction staff in use and administration of Bentley Onsite; technical and on-site support for such staff during construction for the MACH1 pilot project, and software interface (import/export) development (between Bentley Onsite and AASHTO FieldManager). This pilot project is expected to help clarify how 3D-MC should be specified and facilitated on future projects.

\subsubsection{Washington State Department of Transportation}

The Washington State Department of Transportation (WSDOT) management has chartered a multi-disciplinary committee to provide recommendations for implementation. Prompted by contractors' desire to use 3D-MC, GPS machine control is being allowed by special provision on a few projects around the state. WSDOT Standard Specifications stipulate that WSDOT provide surveying control for the projects while construction staking is the responsibility of the contractor. Thus an important consideration for WSDOT is changes to the Standard Specifications regarding surveying/construction staking to ensure that WSDOT 
responsibilities for staking are shifted to the Contractor when GPS machine control is utilized for construction.

It should be noted here that the Washington State Chapter of the American Public Works Association has communicated concerns about potential ramifications to other transportation agencies within the state if WSDOT begins to make EDFs available to bidders. A summary of their concerns and suggestions are mentioned below in relation to liability.

\subsubsection{New York State Department of Transportation}

It seems that the NYSDOT is one of the most aggressive STAs with respect to pursuing a solution for facilitating 3D-MC implementation and GPS technology in general, primarily by making EDFs available to contractors. NYSDOT has administered at least 8 pilot projects on which contractors have employed GPS machine guidance. Although contractors generally led in the championing the use of GPS machine guidance, responsibility for generating the required electronic design files was not exclusively assigned to either NYSDOT or the contractor. In order to facilitate future use of the GPS technology, NYSDOT has changed its standard specifications to allow for use of 3D-MC. NYSDOT's experience indicates that the appropriate projects are those involving movement of some sort of earth or granular material. Avoidance of buried utilities (assuming locations are accurately documented) is another noted desirable use.

NYSDOT's update of their standard specifications makes reference to 1) terminology associated with new survey and automated equipment operations, 2) requiring the Contractor's review and verification of proposed terrain model data, when provided, prior to beginning of field operations, 3) supplemental site surveying (post award), and 4) new requirements surrounding roving GPS inspection units. Regarding GPS inspection units, the specification calls for the Contractor to provide RTK GPS inspection units for the use of the Engineer and their inspection staff, as well as training of the same, prior to construction, in how to use the equipment. The units must operate from the New York State Continuously Operating Reference System (NYS CORS) Network, and there are numerous detailed requirements regarding data format, storage, and transfer and even battery performance and types of carrying cases. 
Regarding electronic design data, as it relates to construction details, NYSDOT has determined to provide the electronic data, when available. Language specifically addresses the use of DTMs as information of record for assessing performance and compensation. NYSDOT has determined to establish the approved contract design documents (specifications and plans) in the form of an approved printed version and rely upon that paper copy as the reference of record. It is the information in that particular paper set of plans that governs construction requirements until it is updated, approved, and printed again in response to needed corrections or changes. In short, paper rules and any electronic design file is supplemental. This approach is meant to free both the Department and the Contractor to derive maximum benefits from having design data in digital form while maintaining the obligation of the Contractor to perform according to unambiguously established contractual requirements. Later language acknowledges that the Contractor may use such data for AMG as approved by the Engineer through a Contract Control Plan to be submitted and approved before construction field operations commence.

NYSDOT conducted field visits and independent interviews with contractor's personnel, DOT inspection personnel, and designers of the eight projects under construction during the 2007 season, from which a document was generated of lessons learned with respect to the use of automated machine guidance, automated inspection technologies, and the general use of electronic engineering data. Among the observations made regarding AMG are the following:

- Major increases in productivity by as much as $40-50 \%$ are noted primarily for the placement, grading and removal of granular materials.

- Operators introduced to AMG systems become proficient in about a month.

- Field errors are reduced as the computer virtually eliminates hand calculations.

- Contractors can recoup their investment within their first large project and not all machines need to be equipped, only those responsible to ensure the proposed grade. [Note that New York State has a CORS network which obviates the need to purchase base stations]

- The RTK GPS enables contractors to perform continual quality control.

- Waste and rework are significantly reduced. 
- AMG makes grading operations for difficult-to-construct retention/recharge basins much easier to complete.

The document follows with a section of lessons learned regarding automated construction inspection using GPS and rovers and Bentley On-Site inspection software. For greater clarity on these and other points, the reader is directed to the Appendix to read the complete listing of lessons learned.

The compilation of lessons learned contributed to creation of both the specification update for GPS discussed above and a proposal for use of electronic engineering data (EED) which was prepared by the New York State AGC/DOT Subcommittee on Emerging Technologies. A two-year study by the committee resulted in the proposal entitled "Proposal for Use of Electronic Engineering Data in Construction," dated January 2008, which advocates a paradigm shift from 2D paper to 3D electronic plans for relevant NYSDOT projects. The proposal was formulated with input gathered from other State Transportation Agencies through the AASHTO Technology Implementation Group on Automated Machine Guidance; from joint DOT workshop discussions on these topics; from Trimble, Leica, and Topcon; and also from Bentley Systems. The proposal recommends the following list of electronic deliverables to be included in a complete project model thus setting the goal of what is recommended be delivered as a biddable and constructible project model.

1. Finished Grade DTM

2. Top of Subgrade DTM

3. Existing DTM

4. Non-triangulated DTM (if applicable)

5. DTM of Bottom of Bridge Substructure Excavation (or Box Culvert Excavation)

6. Graphics of Existing \& Proposed Terrain Mapping

7. Storm \& Sanitary Sewer Database

8. Alignments of Control Lines, Right-of-Ways \& Boundaries, and Features

In addition, the following list of electronic deliverables is recommended to be included as electronic data in addition to what is in the project model, or by itself for proposal only contracts.

1. Graphics of Details, Typical Sections, Record Plans and Schematics 
2. Excel Spreadsheets of Job File and Quantity Work-ups

3. Electronic copies of Proposal Notes, Specs and Contract Documentation

4. For non-DTM projects, include Lists of Proposed 2D Item Coordinate Locations

5. Electronic Copies of Subsurface Exploration Logs, filed ROW Maps and Sign Face Layout Sheets

Regarding implementation, the proposal estimates that only about $25 \%$ of the yearly NYSDOT projects would be candidates for providing electronic data and that they would be well distributed among the regions. The proposal then acknowledges specific standards that would have to be updated to accommodate the new practice and finally estimates a 2 to 5+ year transition time for regional offices and consultants. In the appendix to the proposal, suggestions documented from a practitioners' meeting are listed for highway design, bridge design, and CADD specific recommendations

\subsubsection{INDOT Developments Regarding 3D-MC}

There is a Team Indiana Project Development Group consisting of INDOT personnel and representatives from the American Council of Engineering Companies (ACEC) of Indiana and from the Indiana Constructors Association (ICA). One of the items on their agenda is how to facilitate stakeless grading on INDOT projects. The current plan promoted within this group is that the contractor will take the 2D EDF and assume responsibility to generate the DTM for their use.

Based on requirements used in several other states, the Team developed a draft specification for changes to Section 105.08 of the INDOT Standard Specifications that would either replace or supplement the existing construction engineering specification. The specification addresses utilization of GPS or robotic total station (RTS) for 3D-MC and specifically refers to "the placement/phase construction of subgrade, subbase, base courses and other roadway embankment materials and in construction of ditches or other planned excavations designed in the project.” The draft specification has the following features:

- Does not require 3D-MC to be used on the project 
- Alerts the Contractor to expect to be independently responsible for developing their own electronic surface model (DTM) to be submitted for review by the Engineer

- While allowing for the fact that in some cases, the Department might provide an electronic surface model for at least a portion of the work, requires the Contractor to release the [design] Engineer and the Department from all liability and for accuracy and conformance to the Contract Documents provided by the Department

- Gives no indication regarding when electronic surface model data might be made available, apparently leaving that decision to be job-specific

- Allows Contractor to use the 3D-MC system of their choice

- Requires Contractor to provide certain evidence that they have the necessary resources and proficiency to successfully utilize their system of choice

- Requires Contractor to provide 8 hours of training on Contractor's equipment

- Requires Contractor make a GPS rover available for Department personnel

- Requires Contractor to provide professional surveying services to resolve discrepancies and to establish control references

- Requires Contractor to maintain Department-established reference points and monuments within project limits

- Does not call for any changes in tolerance requirements

- Requires Contractor to still provide control points and grade stakes at critical points

- Requirement for a written machine control grading plan (including equipment and base station details) one week prior to preconstruction conference

Comments received from contractors regarding the draft specification are as follows:

- Concern that GPS rover may provide inaccurate measurements

- Agreement with the 3D-MC being an option

- Concern about the expense to provide a rover (rovers for multiple projects) for grade checking

- Agreement that responsibility for an accurate DTM stays with the Contractor

- Desire for Department to provide and be liable for adequate and accurate control points for the DTM development 
- Desire to have electronic surface models available

- Concern about requirement to maintain Department references within project limits

- Desire to allow Contractor to identify Department references within

- Suggestion to have Contractor tie in Department control points and monuments before construction instead of having to maintain them

- Concern that grading plan details cannot be confirmed so soon prior to preconstruction conference

- Suggestion of a separate pregrade meeting to establish grading plan details separately from preconstruction conference

The team plans to identify perhaps two projects to serve as pilot projects. One pilot has already been identified - US 31 South Bend to Plymouth — a 5-mile section planned to be let in the August 2008.

\subsubsection{Additional Implementation Considerations Regarding GPS}

Machine control is not impervious to error. There is still a need for surface checking by a survey team to verify that the machine control is working to within satisfactory tolerances. Unlike laser systems, GPS does not require a direct line of sight to the grader or other equipment, but there are restrictions on the placement of the base station. In order to have sufficient reception of satellite signals, the base must have a clear view of most of the sky, particularly above and to the south. Large objects such as trees and buildings in the area will not only block or degrade the signal; it could also reflect the signal, resulting in a phenomenon known as multi-path. While most receivers can compensate for this problem, project managers must take care to design the work to minimize this problem. These restrictions also follow for the construction equipment, although work is typically well away from tall trees and buildings and a temporary loss of satellite signal strength may be less detrimental due to the radio signal from the base station.

Another aspect which can keep a project from using GPS is the lack of a suitable network of control points near the site. There must be sufficient geospatial infrastructure within a reasonable distance to the worksite for GPS to be used. As a site moves further from a control point, the potential for error increases. Temporary control may be established 
by surveyors, but for the quality needed for GPS, time must be allowed to establish a network of adequate quality.

In metropolitan areas, having sufficient control will not be a problem as the National Geodetic Survey, who is responsible for setting benchmarks in the United States, would have plenty of markers. Private companies around the metro Chicago area have base stations extending into the northwest section of Indiana as well. However, in some places in Indiana, such as the forested areas around Brown County, it has been recognized that there is not a substantial amount of control (personal discussion with investigator for JTRP project SPR3081). It will be up to INDOT to decide which projects would be suitable for use for GPS, however, as noted in Section 5.3.1.4, this challenge may soon be an issue of the past once the Indiana CORS network is functioning.

Although GPS machine guidance will reduce or eliminate the need for surveyors to stake a site before work begins, there will still be a need for survey personnel and equipment on site. With the chance of inaccuracies mentioned previously, surveyors will be required to perform grade checks occasionally to assure that the plans have been properly transferred to the surface.

\subsubsection{STA Liability Concerns}

There are a number of specific liability concerns associated with the topics of 3D-MC and the related use of EDFs for completing transportation projects. The issues brought up during the course of this study could be distilled into four overarching areas of concern:

- liability for field errors from operation of 3D-MC machine guidance, i.e., poor performance with the technology,

- liability for performance when utilization of 3D-MC is required, or its use defined in detail, by the contract, i.e., whether specifying 3D-MC constitutes a prescriptive specification and therefore shifts risk to the STA,

- liability for field errors resulting from improper preparation of the design files, i.e., inadequate adherence to necessary design protocols or errors in design file translation, and 
- errors in data on which the design is based, especially at construction limits, i.e., mismatches between DTM coordinates and the field.

The general question as one insurer phrased it is "How does the use of EDFs to facilitate 3D-MC shift the liability needle from where it is now?" For this study, this question was investigated from consultation with an Indiana-based insurer of contractors regarding their perspective and with several STAs regarding how they have chosen to address the liability concerns.

\subsubsection{Liability Status Quo and the Insurer's Perspective}

It is important to note that, as an agency responsible for utilizing the resources of the public to procure services to build and maintain transportation infrastructure, STAs are generally characterized as risk-averse. Because of this reality, construction contractors are accustomed to assuming risk associated with the performance of the services they have contracted to provide. It is customary for construction contracts to spell out that the contractor is responsible to deliver an end product according the design intent, typically represented by quality standards (e.g., strength requirements, dimensional tolerances, smoothness criteria, etc.) even when conditions or technology limitations make it difficult to do so. Otherwise, the work is either rejected or the contractor incurs a penalty. Acknowledgment of this present status quo helps frame the questions regarding liability surrounding the use of EDFs and 3D-MC.

It is overwhelmingly apparent both from references and from information supplied from the STAs that it is the contractors who, from the beginning, have taken the lead in embracing 3D-MC, and they are the ones who in the vast majority of cases have introduced the technology to their owner clients and have urged facilitation of its use through modified design and procurement practices. Many have persevered, even in the absence of special accommodations from the owner, to demonstrate the effectiveness of 3D-MC technology and added to their experience base in the process. By doing so, these contractors are demonstrating a characteristic willingness to take responsibility for the results achieved through their choice of technology. 
There are two aspects to consider related to contractor liability: (1) assurance of project execution and (2) quality of work. An insurer or surety generally stands behind the contractor to protect the project and assure the owner of its execution. The contractor's general liability insurance policy contains a "your work" exclusion, that is, the work product, or rather, the quality of the work product, is not an insurable risk. Therefore, the matter of general liability is not affected by use of a new technology such as GPS machine guidance.

On the other hand, equipment is insurable, and such insurance could be more expensive because of the additional equipment, although probably not much more. Insurance would cover mechanical breakdown of construction equipment and computer systems, such as the GPS machine guidance systems, separately. While the use of advanced equipment combined with the improved work record might translate to savings on liability coverage, such savings would be minor.

\subsubsection{STA Liability in Directing Technology Utilization}

The most urgent matter regarding liability is perhaps that assumed by the STA for directing the use of a particular technology, in this case, 3D-MC or any other critical use of the EDF. The STA may be held responsible for errors or losses incurred by designers, contractors, or subcontractors due to the STA's specifications or administration regarding design or construction methods. In addition, they may be held liable for mistakes or poor performance stemming from shortcomings of a prescribed technology or associated contractual prescriptions. Therefore, careful determination and communication of what the STA requires, commits to, and enforces is important for defining liability boundaries. As has been shown above, STAs have had varied solutions for how to facilitate utilization of 3D-MC and the associated required EDFs. Review of the examples described in Sections 5.3.3.1-5.3.3.6 reveals the following distinct options for the STA:

- Model Definition

o Employ contract language that clarifies the legally binding form and version of the design and clarifies that any EDF, regardless of its source will be considered as supplementary information to be relied upon at the contractor's risk. This provision would establish the form and version of the plans (e.g., 
first generation mylars or a reproduction thereof) that is considered as part of the contract, thus holding the contractor to performance that is unambiguously approved by the STA.

- Employ contract language in design consultant contracts that specifies the design information that should be submitted in electronic form, specifically, which elements of the project should be provided in the form of a $3 \mathrm{D}$ model and in what format(s). In this way the STA can increase the likelihood that 3D models actually capture the original design intent and are not misinterpreted by the contractor or third party when creating a DTM from the 2D plans. The STA also ensures that 3D models are readily available for the elements and tasks of the project that can be delivered more effectively from 3D models. The STA also maintains a place in the file sharing loop and the opportunity to review such files. The counter to this option, though, is that it may narrow the list of qualified design consultants to an unsatisfactory number.

- Technology Specification

o Employ contract language, probably special provisions, to invite the use of $3 D-M C$, specifically GPS-based, on appropriate projects as predetermined by the STA. This approach identifies appropriate projects without prescribing the technology so contractors are alerted early of this option and its impact on bidding and on construction.

o Employ specifications, probably special provisions, which can be referenced if the use of 3D-MC is determined after the contract is awarded. This practice is applicable to instances where the contractor introduces the option of using 3D-MC post award and is given approval to proceed therewith. Such contract language may either be in the original contract for the contractor's advance information or inserted as a contract change when necessary.

o Employ contract language to specify characteristics of allowed GPS-based 3D-MC systems and to stipulate certain quality assurance measures. This practice allows the STA to have some measure of influence on application 
based upon past successful applications, but not to the point of being prescriptive.

- 3D Model Access

o Employ language in both the design and the construction contracts that clarifies that the consultant is to supply specified $3 D$ models to the contractor upon request by the contractor. By this approach, the STA removes itself from the file sharing transaction while alerting each of the other two parties to the expectation of cooperation on this point.

o Employ contract language that places all efforts to obtain a DTM in the hands of the contractor alone. This provision removes the STA from both the 3DMC utilization decision and from the EDF acquisition transaction. The clear downside here is that the STA may expect the contracting firm to incur higher costs and consume more time in obtaining or producing the desired DTM(s). If the contractor desires to begin with an electronic file from the designer, then the STA's permission will still be necessary.

o Employ contract language that specifies that the STA will make the 3D model information created by the designer available to the contractor upon request. This provision would keep the STA in the communications loop and in a position to inspect the quality of the design data provided, even if not formally approving such data. The STA is, however, placed in a vulnerable legal position by handling the data and might in this instance incorporate release forms to clarify their non-liable status in the transmission.

- Responsibility for Quality

o Employ contract language that clarifies the contractor's responsibility for confirming the accuracy of the DTM and providing performance that meets quality specifications regardless of the STA's role in facilitating the contractor's acquisition of the EDF. This provision would be consistent with the contractor's normal responsibility regarding quality, and makes it clear that the STA is not in any way assuming any of that responsibility by their assistance in acquisition of the EDF. 
o For pilot studies, obtain agreements from technology providers to support the project by assigning a technical consultant to provide training and help address problems that may arise. This action can help to avoid or readily overcome those technical problems that result primarily from lack of experience or inadequate planning as opposed to product deficiencies. This action is extremely important if any software or field equipment is being used for the first time or in a new way. MDOT, for example, had consultants from Bentley and Trimble during their first pilot study to help with preparation as well as during project execution. The presence of such personnel encourages problem solving over assigning blame when something goes awry. Vendors who were sources for this study have confirmed their willingness to participate in pilot studies. The STA would be wise to reserve the right to review and accept or reject the experience record of the individual(s) assigned to provide consultation.

These options are listed for consideration and to illustrate the critical decisions that other STAs have made to limit their liability when 3D models and 3D-MC are relied upon to do construction. When crafting changes in the specifications, it is important to consider both what is stated and what is not stated, and care must be taken regarding how contract language shifts liability to another party. While there was an impression that the design consultant community did not favor providing 3D models due to liability and perhaps data security concerns, further inquiry by the Investigators revealed there is indeed a general willingness to provide whatever information is required by INDOT. However, the design consultants do desire clear direction regarding the specific information needs that such models should satisfy. Since not all aspects of a design need to be modeled in three dimensions, clarity regarding the essential data would help design consultants to complete their work both effectively and efficiently.

It would be ideal from a process and design integrity perspective for the design consultant to produce the necessary DTM from the beginning, not only to satisfy parties downstream, but to also enhance the opportunity to recognize modeling errors before the design is released. Toward the end of achieving this goal, the Investigators suggest that one 
possible near-term solution to increase the number of designers comfortable with such a revision in the expected deliverables is for INDOT to encourage or facilitate partnerships between design consultants and engineering service providers (usually surveying firms) who are currently more experienced in performing the task. The benefit of such a relationship is that the design intent may be more effectively translated from the 2D design model to the 3D model and also greater confidence can be placed in the field accuracy of the DTM. Individual design firms may develop greater comfort with this new paradigm after the experience of partnering in this manner to deliver designs. Regardless of how a design consultant delivers the 3D model, the STA may expect a need to adjust their expectations regarding the design time schedule. Because INDOT routinely interacts with their design consultant and construction contractor communities, they are in a good position to bring the parties involved together to craft a roadmap toward achieving a mutually appealing process that most benefits delivery of the project. The matter of liability would, of course, be satisfactorily addressed in the process.

\subsubsection{Implementation Implications for Other Agencies}

As a public agency, an STA has a sphere of responsibility that goes beyond the simple legal bounds of individual contracts. An STA's leadership as an agency that contracts for construction within the state carries considerations of other public agencies which contract for delivery of transportation projects although the STA is not legally obligated to them. This responsibility is illustrated through the discussions of EDF availability to the contractors in the state of Washington.

Apprehensive of the impact on local agencies receiving FHWA funds, the Division 1 Subcommittee of the Washington State Chapter of the American Public Works Association registered their concerns about a draft specification considered by the AGC/WSDOT Administration Team (Admin Team) for providing electronic digital terrain models or other design files to bidders during the bid period. A discussion paper representing input from 27 local agencies was submitted to the WSDOT State Construction Engineer in January 2008, and the following nine points were delineated and are summarized here for reflection: 
- Encouragement to treat providing electronic data during the bid period as a separate question from providing electronic data after the award of the contract

- Concern about bid process protests due to the provision of electronic data during the bid period requiring the Engineer or other technical staff to provide technical assistance to Bidders

- Risk of an uneven playing field for Bidders due to varying levels of technological capability and resources among Bidders

- Risk of inconsistency in the data delivered to Bidders due to varying levels of technological sophistication among designers

- Question of whether there was a consensus among Contractors regarding the type of data desired

- Potential for detrimental effects on how designers perform their work and competition in the design industry if data format is standardized

- Potential lack of time and funding to support purging of files of early versions of the design and the preparation of electronic files before release (original and updates)

- Increased costs to cover liability attached to DTMs since they are an interpretation of survey data by a licensed professional

- Increased design costs due to the increased standard of care required if liability is attached to design files

This list of concerns includes several areas of increased or shifting liability that might occur if EDFs are made available. In order to minimize or avoid these potential negative impacts, the APWA Division 1 Subcommittee requested that WSDOT 1) test the idea of providing electronic design data by conducting pilot projects and including the provision in the General Special Provisions before amending the Standard Specifications, 2) try only providing the electronic design files after the award first, 3) invoke better liability protection by enhancing their disclaimer statement and clarifying that the electronic data is provided without warranty and not part of the Contract Document, 4) develop language to more specifically define the type of data to be provided, 5) continue to explore the impact on all agencies dependent on the standard specifications, and 6) include a technical advisor in 
future discussions of their plans for implementation. Such advice might be considered by any STA making plans to facilitate 3D-MC by making EDFs available to the contractor(s).

\subsubsection{Summary on Liability}

In summary, the 3D-MC technologies are considered reliable as long as the DTMs are prepared correctly. None of the entities consulted saw a need for special additional insurance coverage to support pilot projects. Since the contractors are typically responsible for employing effective methods in order to meet requirements, the share of liability between the STA and the Contractor need not be shifted if the STA clarifies that they are not aiming to move it by appropriate language in the contract. The STA just needs to avoid being overly prescriptive understanding that the technology is capable of yielding satisfactory results when used properly.

It appears that the more complex liability issues stem from how much responsibility the STA and design consultants want to assume for the correct development and accuracy of the EDF. STAs are trying different approaches in accordance with their tolerance for bearing liability, from providing the EDFs to the contractor to leaving the contractor to obtain or create the DTM on their own. Overall response to this dilemma is to clarify that the EDF is not a contract document and that the contractor is responsible to confirm the DTM's accuracy. Since placing responsibility for creating the DTM on contractors is not the most desirable practice from an efficiency standpoint, the alternative scenario of design consultants contracting with engineering service providers who currently have greater expertise to create the DTMs for 3D-MC seems to be a feasible solution for getting the 3D EDF delivered and field-verified up front. As noted above in Section 5.3.6.2, it may be well worth the effort for INDOT to use its relationship with the industry to facilitate this and other conceivable alternatives in order to grow the pool of design consultant candidates from the local region who are capable and willing to satisfy requirements for useful EDFs.

One philosophical note regarding the issue of liability is that the new working environment may mitigate the increased liability potentially assumed by any party. One important impact noted by an STA representative regarding the use of GPS machine guidance is that it drives the sharing of data for the development and mutual use of the EDFs 
and thus enhances communication between parties and diminishes the traditional adversarial relationship. Both written and verbal testimony of this opinion has been noted from various advocates of the 3D-MC technology during the course of this study. If those adversarial relationships indeed are given up for a shared interest that works cooperatively through obstacles and problems rather than resorting to finger-pointing, then much of the liability question may become irrelevant.

\section{RECOMMENDATIONS FOR UTILIZING EDFs}

In light of the motivation from industry and the information obtained to address the key issues addressed in this study, INDOT should proceed toward implementing the use of EDFs to achieve a seamless PDP work flow and to facilitate utilization of 3D-MC on INDOT projects. This section is therefore devoted to recommendations for implementation. INDOT is already incorporating the necessary software solutions into its in-house resources, but real transformation can only be realized if interactions with outside organizations (e.g., utilities, design consultants, and contractors) are included in the improvement of work processes through incorporating these new tools. First, there are options that INDOT should consider in light of the agency's tolerance for liability in promoting more extensive technology adoption by local design consultants and construction contractors. From there, the agency should pursue a well-crafted plan of trail-and-assessment because there are numerous new tools and processes that may be impacted by their use. The trials should be planned not only to facilitate transformation of INDOT's work processes, but also to accelerate broader technology adoption by local designers and constructors. It has been shown that today's software has adequate modeling and document control features to support interorganizational collaborations and the state is also committed to building the Indiana CORS network to realize GPS technology advantages, so there is every reason to promote the industry's move to keep step with their counterparts in other regions of the country. Following is a list of stances INDOT can take and then a list of recommendations toward implementation. 


\subsection{Continuing Software Adoption and Business Transformation}

As noted in Section 5.2.3.1, INDOT is already in the process of adopting a wider range of what the Investigators have dubbed CIM tools that are offered by Bentley Systems, Inc. and the direction of development of these tools should well support 3D modeling for various purposes and sharing EDFs both in-house and with other organizations. Continuing in this direction is essential to positively transforming how INDOT does business with its industry partners. Although the adoption should be done in phases, the end goal should be to adopt new tools and updated work processes that span the project life cycle, including the operations and maintenance phase. While near term investments for new systems and training may be expensive, the downstream improvements in efficiency should soon be realized if INDOT, as an organization, wisely maximizes its learning opportunities.

\subsection{Facilitating 3D-MC}

In relation to the use of GPS machine control in construction projects, there appear to be several courses which the state could decide to follow. Three are presented below, with their pros and cons. The options listed are not the only choices the state has, but represent the major avenues to follow.

\subsubsection{Maintaining the Status Quo}

The first option is to follow a hands-off approach, allowing the marketplace to decide the use of any technology in construction. This approach leaves the industry to adopt the 3D-MC technologies at its own pace, while not appearing to favor any companies which utilize it. However, this option also gives the state the least influence over the quality and accuracy of the technology's use. Furthermore, as some contractors are already sold on the technology, regional INDOT construction offices would be left without a consistent approach for working effectively with such contractors, so the realization of bidding benefits would be greatly delayed.

If a contractor decides to use GPS machine control without the STA's awareness or approval, there could be many possible issues. If the company has little experience with the technology, there could be an increase in errors compared with those from not using it. This 
is just one of the liability issues that the state will need to consider as GPS machine control use becomes more common. If there is insufficient survey control near the project, or the site itself is unsuitable for GPS reception, the state may not realize any of the perceived benefits. Finally, the state probably would not benefit from any of the cost savings which machine control may provide. For this path, the state should, at the very least, incorporate minimal GPS standards in their project manuals.

\subsubsection{Designating Projects as 3D-MC-Optionable}

Following the approach used in Minnesota, for this second option, INDOT would review the construction site to decide its suitability for GPS machine control. This includes issues such as sufficient geodetic control close to the site, the ability to create a stable base station (if CORS is not yet available), and the chance that the equipment could run into errors in receiving signals from the satellites, including trees or structures blocking the signal or creating multi-path error. In order to pursue this path of implementation, the state will be required to have knowledgeable personnel engaged in the site selection process. These persons will need to be well versed in the requirements of GPS control and machine guidance technology, and will be a key to ensuring that these requirements can be met on the project.

\subsubsection{Requiring 3D-MC on Suitable Projects}

For this final option, suitable projects for GPS machine control are identified and utilization of the technology is required in the contract. This final option gives the state the most control over the use of the technology, but may also cause the most difficulty for the state. By requiring the use of machine control, the state will effectively exclude many design firms and contractors from competition who may not yet be experienced with the relevant technologies, or are not able or willing to make the investment.

\subsection{Recommendations for Pilot Studies}

STAs should proceed carefully when pursuing implementation. The experience in Michigan (see MACH1 Lessons Learned in Appendix) is a prime example of how a simple pilot 
project can run into difficulties, due to reasons other than inadequacy of a new technology or process, which hinder the desired outcome. Although the overall goal is to support a seamless collaborative PDP, the array of individual objectives for utilization of EDFs prompt that further examination occur through perhaps several stages of implementation. The number of possible project team participants involved and the number of individual new technology tools (software and hardware) can make assessment rather complex and thus inconclusive if several new practices are implemented on one project. Based upon the information gathered regarding technology and practice from 3D-MC technology vendors, design modeling and project management software vendors, design consultants, providers of survey engineering services, contractors, and other STAs, the following recommendations are offered as important considerations for pilot projects.

\subsubsection{Scope of Pilot Studies}

INDOT should conduct several pilot studies with focused objectives that allow them to separate the impacts of the various ways in which new technology or process can be leveraged. For example, the question of making the 3D model(s) available during bidding is indeed a separate question from making it available for 3D-MC. A pilot study of the former may focus on how well the 3D model facilitates INDOT's internal PDP processes as well as the outcomes of the bidding process. A study of the latter would focus on preconstruction and construction phase activities and INDOT's learning curve when it comes to adopting methods that maximize benefits from the new field automation.

For the internal process pilot, INDOT should assess leveraging of the EDF during the planning and design phases. Initial learning might be accomplished by first making use of a historical project to simply study how effectively the EDF can be handled internally and with design consultants and utility partners. The file sharing functions and security and version control features of ProjectWise would be a major focus of assessment. Confirming that the correct format and versions of the EDF are made available to the correct project participants so workflow is enhanced would be the key objective. Review of the historical project also provides an opportunity to establish a sound basis for cost analysis during later pilot projects. Success with the historical project could then be followed with a pilot study for a new project 
or projects. Including some in-house design projects for either the historical or new project study will provide firsthand learning of the implications of the 3D modeling software technology. This experience will also benefit the future refinement of specifications.

\subsubsection{Project Selection}

As NYSDOT has asserted from their experience, INDOT should identify projects that have a major component of earthwork, i.e., placement, grading and/or removal of granular materials or major excavation or embankment operations. Such projects would maximize opportunities for construction operations to benefit from 3D-MC. Other types of projects are still candidates if the agency is only assessing general work process benefits from the sharing of design files.

\subsubsection{Draft Specifications}

INDOT should proceed with development of the current draft specification from the Team Indiana Project Development Group consistent with the input received from ACEC and ICA to facilitate successful project outcomes. As noted above, this new specification currently places responsibility for the DTM on the contractor, and that is a requirement to weigh carefully in the light of this study. Regardless, specification language should make absolutely clear which version of the design is the design of record (either paper document or protected accessible electronic version) and that the contractor is responsible to confirm that they have checked the design they utilize for conformance to the design of record. The option of including new line items in contracts for technology alternates, i.e., using and not using 3D-MC, is an additional consideration but may be unwarranted since it is arguable that no essentially new work items are being created. As an additional note regarding design requirements for 3D-mandated projects, INDOT may also prescribe specific project components which should be modeled in 3D to maximize construction benefits from the EDF so such deliverables may be specified in design RFPs. The reader is referred to a brief draft proposal document from the NYSDOT entitled "Requirements for Electronic Data to be Supplied to Construction" and made available by the AASHTO TIG (http://www.aashtotig.org). 


\subsubsection{Maintain Collaborative Oversight of Implementation}

The final recommendation from this study is that INDOT maintain a dedicated team of agency personnel and industry representatives to monitor the success of pilot projects and the transition to the new model for collaboration through sharing of design files. Currently, the ICA/INDOT Joint Cooperative Committee is spearheading efforts to develop appropriate specifications and identify pilot studies. Since this committee has a broader mission, perhaps a subcommittee or task group of similar representation should be commissioned to oversee implementation and assessment of pilot projects for developing INDOT's knowledge and practices regarding EDFs and 3D-MC. This group would be responsible for defining the objectives for each selected pilot project, for securing the involvement of technology vendors (who have voiced and demonstrated a strong willingness to support pilot efforts), and for gathering performance data and lessons learned to be incorporated in either future INDOT pilots or standard specifications and practice. This group should also address the broader range of applications for GPS because of its emergence as the most advanced technology for positioning and dimensioning the design model in the field.

\section{CONCLUSIONS}

The aim of this study was to gather information regarding technology, practices, and experiences surrounding the leveraging of access to electronic design files including a particular emphasis on facilitating the use of three-dimensional machine control on transportation projects and then to make recommendations to INDOT regarding implementation. This study has noted that the building construction industry is currently being transformed by adoption of Virtual Design and Construction and Building Information Modeling tools and processes which facilitate automation, better access to project information, and higher degrees of cooperation between project partners. These concepts may be translated to the civil infrastructure domain in the form of what the Investigators have termed Civil infrastructure Information Modeling or CIM. Indeed, it has been further confirmed that the industry is moving in this direction as a variety of software tools are emerging from the leading CADD vendors and other third party vendors (e.g., electronic data 
security) to enable seamless project collaborations via sharing of design information in various forms and formats. Considering the fact that INDOT has already begun investing in incorporating many of these tools to support its Project Development Process, the Investigators conclude that the agency should proceed toward establishing an improved way of doing business with its project partners as supported by these CIM-enabling technologies. Review of INDOT's Project Development Process reveals several opportunities for file sharing and performing tasks through computer automation.

A review of STA experiences reveals that contractors are embracing 3D-MC and are typically initiators of implementation on transportation projects. Numerous STAs have responded with efforts to draft new special provisions, revised specifications, and pilot projects to further study the benefits of 3D modeling and 3D-MC. Already accustomed to bearing responsibility for selecting effective construction methods, contractors, as they request technology accommodations, are not demonstrating any desire for STAs to take on greater liability for facilitating access to 3D project models. However, there are numerous examples of appropriate contract language that limit the STAs responsibility for design accuracy and that direct the contractor to confirm such model information before construction. As the present champions of 3D-MC, contractors appear to be more concerned about improving overall efficiency by having the DTM prepared during the design phase and then ready for multiple uses rather than about shifting greater liability to design consultants and STAs. There are indications that design consultants in the Indiana region are willing to provide 3D models but would look for direction from INDOT in clarifying the critical design model data needs.

The complexity of opportunities for changed processes and improvements calls for careful staged implementation through a program of pilot projects which should be overseen by a specially assembled subcommittee or task group representing INDOT, design consultants, and contractors. Vendors of modeling software and of 3D-MC systems have voiced and demonstrated eagerness to provide technical support to such pilot projects. The oversight group should be responsible for setting the learning objectives for each pilot project and for assembling data on the results and lessons learned to be carried forward in transforming the way INDOT incorporates CIM technologies to deliver its projects through more seamless and effective collaborative processes. 


\section{LIST OF REFERENCES}

AGC (2006). The Contractors' Guide to BIM, $1^{\text {st }}$ edition, Associated General Contractors (AGC) of America, Arlington, VA,

American Council of Engineering Companies

http://www.acec.org/publications/lastword2008/lw012408.htm

Anon (2005). "Automatic Grade Control Systems Replace Old Earthmoving Problems with New Ones," ENR: Engineering News Record, vol 255, no 4, August 1, McGraw-Hill, 20.

Anon (2008). "Balancing BIM: An Owner's Guide to the Benefits (and Obstacles) of 3D, 4D and BIM Design," The VOICE: The Official Magazine of The Construction Users Roundtable, Matrix Group Publishing, Houston, Texas, Spring 2008, 18-23.

AASHTO (2007). AMG: Automated Machine Guidance-Advancing Safer, Faster, More Accurate and Less Expensive Roadway Construction, a brochure by the Technology Implementation Group (TIG), American Association of State Highway Transportation Officials, http://www.aashtotig.org.

Bentley Systems, Inc. (2008). The Year in Infrastructure 2007, Bentley Empowered, Exton, PA, 74. (http://www.nxtbook.com/nxtbooks/bemagazine/beawards07/).

Bernold, Leonhard, "Spatial Integration in Construction", Journal of Construction Engineering and Management, October/November 2002, 128:5

Brown, Dan (2001). "Satellite Dozing: GPS Systems Can Make Earthmoving Easy as Pie," Heavy Equipment News, July, Cygnus Business Media, Fort Atkinson, WI, 76-82.

Campbell, D. A., (2006). “Modeling Rules,” Architecture Week, online weekly, no. 307, October 11, Artifice, Inc., T1.1.-T1.2. http://www.architectureweek.com/2006/1011/tools_1-1.html

Daoud, H. (1999). "Laser Technology Applied to Earthworks." ISARC '99, Proceedings of the $16^{\text {th }}$ IAARC/IFAC/IEEE International Symposium on Automation and Robotics in Construction, C. Balaguer, ed., Universidad Carlos III de Madrid, Madrid, Spain, September 22-24, 33-40.

Do, Won-Seok, Oloufa, Amr A. and Thomas, H. Randolph (1999). "Evaluation of Global Positioning System Devices for a Quality Control System for Compaction Operations,” Transportation Research Record, n 1675, 67-74. 
Eastman, Chuck, Teicholz, Paul, Sacks, Rafael, and Liston Kathleen (2008). BIM Handbook: A Guide to Building Information Modeling for Owners, Managers, Designers, Engineers, and Contractors, John Wiley \& Sons, Hoboken, New Jersey.

Fischer, Martin and Kunz, John (2004). The Scope and Role of Information Technology in Design and Construction, CIFE Technical Report \#156, February, Center for Integrated Facility Engineering (CIFE), Stanford University, 19 pages, (http://www.cife.stanford.edu).

Fiscor, Steve (2000). "San Miguel's Dozers Get It Right the First Time," Coal Age, September, Vol 105, no 9, Mining Media, Inc., Jacksonville, FL, 52-56.

Flinn, J. A., Fileccia, D. G. (2006). "A Next Generation Mining Machine Guidance and Constrol System,” Mining Engineering, Vol 58, No 12, The H. W. Wilson Co., 30-34.

Flinn, J. A. and Waddell, C, and Lowery, M. A. (1999). "Practical Aspects of GPS Implementation at the Morenci Copper Mine," Proceedings of ION GPS-99, $12^{\text {th }}$ International Meeting of the Satellite Division of the Institute of Navigation, Nashville, Tennessee, Sept. 14-17. 915-919.

Fortner, Brian (2008). "Special Report: Are You Ready for BIM?"Civil Engineering, Vol 78, No. 5, ASCE, 44-57.

Garrett, Rodney (2007). "Project Profile: PennDOT About to Embrace GPS Technology,” Grading \& Excavation Contractor, January/February, Forester Communications, Inc., Santa Barbara, CA, 69-72. (also at http://www.GradingandExcavation.com)

Hampton, Tudor, (2005). "Right in the Operator's Seat," ENR: Engineering News-Record, McGraw-Hill, October 3, vol 255 no 13, 44-47.

Jonasson, Snaebjorn, Philip Dunston, Kamal Ahmed, Jeff Hamilton (2002). "Factors in productivity and unit cost for advanced machine guidance," Journal of Construction Engineering and Management, Vol 128, No. 5, ASCE, 367-374.

Leick, Alfred, GPS Satellite Surveying, $3^{\text {rd }}$ Edition, John Wiley \& Sons, Hoboken, New Jersey, 2004

Makkonen, Tomi, Kelervo Nevala, Rauno Heikkila, "A 3D model based control of an excavator”, Automation in Construction, 15, 2006

Navon, R. and Shpatnitsky, Y (2005), "A model for automated monitoring of road construction, Construction Management and Economics, November, 23, Taylor \& Francis, 941-951. 
NCHRP (2007). NCHRP Synthesis 372: Emerging Technologies for Construction Delivery, by John J. Hannon for the National Cooperative Highway Research Program, Transportation Research Board, Washington, D.C., 121 pp.

Oloufa, Amr A., Ikeda, Masaaki and Oda, Hiroshi (2003). "Situational awareness of construction equipment using GPS, wireless and web technologies." Automation in Construction, vol 12, No. 6, Elsevier, 737-748.

Oloufa, Amr A., Do, Won-seok and Thomas, H. Randolph (1997). "Automated monitoring of compaction using GPS,” ASCE Construction Congress Proceedings, Managing Engineered Construction in Expanding Global Markets, Proceedings of the 5th ASCE Construction Congress, Oct 4-8, Minneapolis, MN, ASCE, 1004-1011.

Peyret, Francois, Bétaille, David, and Hintzy, Gaëtan (2000). "High-Precision Application of GPS in the Field of Real-Time Equipment Positioning," Automation in Construction, Vol.9 No. 3, Elsevier, 299-314.

Sawyer, Tom, "Safeguarding Data has Companies Locking Digital Files”, Engineering News Records, March 6, 2006, vol 256, no 9, McGraw-Hill, 28-30.

Steynfaard, DJ, New Developments on Mine Planning and Grade Control at Sishen Iron Ore Mine, Journal of the South African Institute of Mining and Metallurgy, 103, Jan-Feb 2003

Tserng, Hui-Ping and Russell, Jeffrey S. (1997). "Instantaneous Motion Planning and Controlling Tool (IMPACT) for Construction Equipment," ASCE Construction Congress Proceedings, Managing Engineered Construction in Expanding Global Markets, Proceedings of the 5th ASCE Construction Congress, Oct 4-8, Minneapolis, MN, ASCE, 1020-1029.

Tserng, H. Ping, ran, bin and Russell Feffrey S. (2000). "Interactive path planning for multiequipment landfill operations" Automation in Construction, v 10, n 1, 155-168.

Zeyher, Allen (2002). “Just Drive,” Roads \& Bridges, April, vol 40, no 4, Scranton Gillette Communications. (http://www.roadsbridges.com/Just-drive--article3076) 


\section{APPENDIX}

This section contains copies of documents and other information either collected or made available from various agencies regarding their experience with utilizing electronic design files and/or facilitating the implementation of 3D-MC on transportation construction projects. The documents are listed in the following sequence.

- $\mathrm{Mn} / \mathrm{DOT}$ District Checklist (for Applicability of Machine Control)

- MACH1 Lessons - Michigan DOT lessons learned from summer 2007 pilot projects.

- Summary Of Information Learned From 2007 Projects Using Automated Construction \& Inspection Technologies - New York State DOT lessons learned

- Review of STA Electronic File Procedures 


\section{Mn/DOT}

\section{District Check List}

1. Is GPS coverage on the project:

- good - potential for machine control.

- fair - provide alternate models (minimal work to Mn/DOT) and note in special provisions that it's a potential problem.

- poor or none - list in special provisions that this project is not supported for machine control.

2. Is the existing ground information:

- DTM covers all construction area - potential for machine control.

- DTM only covers partial areas. - may be a candidate but should have exclusions listed in special provisions.

- No DTM information - list in special provisions that this project is not supported for machine control.

Note DTM can be either a TIN file from Photogrammetrics or district field generated. LIDAR only data is not desirable at this time as it does not have the required accuracy.

3. What is the dollar value of grading / amount of earth to be moved?

- More than \$?? - Definite candidate as contractor will want to use it.

- Between -

- Less than \$?? - Cost benefit to contract and Mn/DOT minimal. Can be listed as contractor option.

4. Who designed the project?

- Consultant - Need to review data on a case by case basis.

- In-house

5. Does the project have cross sections?

- Yes - still a candidate.

- No - difficult to make a non-pavement model. 


\section{$\mathrm{Mn} / \mathrm{DOT}$}

6. Were the cross sections done using standard criteria? If not, what was used? Cite specifics.

7. What percentage of sections have hand modifications in the top of proposed finish grade?

- $0-5 \%$ Average time to create model.

- $5-10 \%$ Time to create model increases.

- Above $10 \%$ Time to create model increases substantially.

8. What percentage of sections have hand modifications in the subsurface?

- $0-5 \%$ Average time to create model.

- $5-10 \%$ Time to create model increases.

- Above $10 \%$ Time to create model increases substantially.

9. Type of projects/part of projects to be done in GEOPAK Site

- All Ponds, parking lots, trails non adjacent to highways, requires minimal time to create a models.

10. Currently no machine control being done for parts of a projects with grading around approach treatments around Bridges and excavation around walls. These should be listed as exceptions in the special provisions. 


\section{Summary}

The project was not as successful as hoped. The Contractor used very little machine controlled grading on the project due to the issues outlined below. We have learned a great deal from the project and are working with those involved to solve issues to improve the process. All involved are interested in the selection of a project to pilot the technology on next construction season.

\section{Project Selection}

1. In-House Design.

2. Significant Earthwork.

3. MDOT Inspection.

4. Should have considered GPS signal obstruction from trees.

5. Need to consider cell phone coverage if CORS is specified.

\section{Beyond Our Control}

1. Feb. 9, 2007 Best Source Justification Approved by Larry Tibbits later denied by AdBoard.

2. Feb.15, 2007 Approved to Advertise RFP for 1 week.

3. April 3, 2007 Ad Board Cancelled Bentley contract not approved until April $17^{\text {th }}$.

4. June 2007 Contractor's GPS equipment stolen (2 weeks lost).

\section{D Modeling}

1. Performed by Bentley. Behind schedule due to events 1-3 above. Able to deliver by Contractors drop dead date of June 1, 2007.

2. GEOPAK to Trimble TTM (Trimble Terrain Model) export had inconsistencies. Bentley, Trimble, Design Surveys and Design GEOPAK investigated for a week. Solution was to do GEOPAK to XML.

\section{GPS \& CORS}

1. Half day or more training on GPS equipment should have been scheduled. Initially thought that this would be covered during OnSite training.

2. Trees on the project made for limited GPS satellite visibility.

3. Contractors GPS hardware/software.
a. No air card capability for real time correction on the machine. 
b. Initially needed software upgrade to read the MDOT GLONASS signal.

c. Contractor set up base station to read CORS correction then reformat to Trimble and broadcast to machine. Resulted in 1 second latency on grader.

d. In the end the Contractor had to run an independent base station instead of running from the CORS.

4. CORS signal had to be split to send out a separate signal with elevations corrected for the project. This could be addressed through GPS localization.

5. On future projects make sure proper cell coverage.

6. Trimble Support was provided by new representative that had just left Topcon who was not yet familiar with Trimble equipment.

\section{Bentley OnSite}

1. Experience latency in obtaining coordinates that was longer then expected.

2. Time needed to put on and hook up equipment was too lengthy (1/2 hour). Once on would want to inspect/stakeout for $1 / 2$ day. Job was not large enough to support that amount of work.

3. Elevations seemed to fluctuate when running from CORS.

\section{OnSite to FieldBook Interface}

1. Improve FieldManager Administration understanding of the data and import process. Staff was not clear on the possible types of data that could be exchanged between Onsite and FieldBook.

2. More inclusion in discussions between Bentley and InfoTech.

3. More support needed for Construction Inspectors.

4. Improve training to Construction Inspectors for the OnSite to FieldBook interface. Have specific written steps.

5. Be sure OnSite and FieldManager are using the same reference data (item and proposal data)

6. Availability of Bentley and InfoTech Support staff was good.

7. All those involved (MDOT and NonMDOT) were positive and wanted to make the project a success.

\section{Machine control Grading - Notes from IHEEP}

1. Contractors paying $\$ 10,000 /$ lane mile to re-engineer from paper back to electronic data.

2. No stakes necessary but makes hard for inspectors almost mandates use of GPS for inspection staff.

3. Specifications should say that Contractor must share resulting model with Agency. 
4. NYDOT requires Contractor to provide a GPS unit to the DOT for inspection and stakeout.

5. Can DOTs define a "model"? MNDOT just providing clay grade and finish DTM surfaces to Contractor.

6. Cold Springs NY Contractor

a. 50\% gain in productivity with Machine control (earthwork projects)

b. No stopping for grade checks

c. Night work not an issue since there is no need to see stakes.

d. Less fuel consumption

e. Less [wear] on equipment

f. Contractor can do entire job once a week with AsBuilts 


\section{SUMMARY OF INFORMATION LEARNED \\ FROM 2007 PROJECTS USING AUTOMATED CONSTRUCTION \& INSPECTION TECHNOLOGIES}

The NYSDOT conducted field visits and independent interviews with contractor's personnel, DOT inspection personnel, and designers of eight projects which were under construction during the 2007 season. The following summarizes what was learned from the observations and discussions as it relates to the use of automated machine guidance, automated inspection technologies, and the general use of electronic engineering data.

\section{A. AUTOMATED MACHINE GUIDANCE (AMG)}

1) AMG Technology is provided by one of three primary survey vendors within NYS. Trimble appears to be the most widely used, and Leica and Topcon are also used. Survey positioning of the equipment is accomplished either by GPS or by Robotic Total Station and laser level technologies. Equipment manufacturers can connect the hydraulic controls of the equipment blades to the on-board computers to provide either directional and grade guidance to the operator, or can switch to allow the computer to control the operation of the blade (not operational control of the entire machine).

2) Either the computers of AMG utilize a digital terrain model (DTM, aka TIN) of the proposed surface to be constructed, or it uses alignments, profiles and templates to guide cut or fill operations in the field. This suggests that on simple linear grading or trenching operations, that the contractor may only need an alignment, profile and typical section without the inclusion of a DTM surface.

3) Contractors are experiencing major increases in productivity associated with the use of AMG primarily for the placement, grading and removal of granular materials. Field observations note that most major excavation or embankment operations which used AMG, were running non-stop at full vehicle speed for 8 to $12+$ hours a day. This is possible because they did not have to wait for grade stakes to be replaced, they had fewer obstacles such as stakes and people on the ground to be careful driving around, and the operators had full time access to the grade information they need to direct the operation. This suggests that overall productivity on these types of operations could increase by $40-50 \%$. This productivity increase is measurable by contractors, but due to the competitive nature of bidding on DOT projects, this proprietary information is not shared.

4) One more obvious savings in both time and money on construction projects which use AMG is the reduction in the need for grade and alignment stakes. Construction sites are no longer obstructed by numerous stakes scattered across the site which thereby eliminates them as obstacles for operators to have to constantly avoid. This elimination 
of stakes also reduces the frustrating delays associated with waiting for the stakes to be reset due to equipment hits or vandalism. AMG has the advantage of being used on locations with poor site distance, and during poor weather or night time conditions.

5) Contractor operators of heavy equipment which is "guided" by AMG quickly learn the use of the on-board computers in about a week, and become proficient in its use within about a month. Those who were asked about say they love it once they learned it and would not want to go back to the old ways. They feel they have the power of all the information they need at their fingertips whenever they need it without depending upon surveyors to stake out the project site. Overall, operators are quickly adapting and embracing AMG.

6) AMG does allow for operation of heavy equipment by less experienced operators, but contractors still prefer the more experienced since they tend to take more pride in their work.

7) One difficulty encountered by both contractors and DOT Inspectors is that due to no longer providing stakes in the field that field personnel have difficulty positioning themselves as to where they work needs to be positioned. This challenge has been overcome by the use of GPS Rovers to provide visual feedback as to locations of proposed work.

8) Many changes that technology introduces to production workflows are met with resistance by construction veterans who are comfortable with the established ways of doing business. On these AMG projects, the younger staff adapted more quickly to the newer technologies, but even the most experienced veterans are recognizing the positive benefits of greater efficiency, better quality and safer field operations. This change is evolving as those veterans use the technology and can test its reliability and accuracy.

9) By the use of AMG, it virtually eliminates the need for survey personnel to set stakes and job Foreman to constantly check grading elevations. In trenching operations, AMG eliminates the need for personnel to climb down into the trench to check excavation grades. This reduction in the need for human interaction around heavy equipment has a very positive effect on increasing the safety of the work operations by reducing the opportunity for accidents. Operators can spend more time being aware of their surroundings when they don't have to watch grade stakes. AMG also allows Foreman to attentively supervise field operations instead of needing to constantly check grade elevations.

10) AMG has virtually eliminated hand calculations in the field which can lead to errors, and has reduced the dependency on human judgment for the interpolation of the designer intent in the field. Computers are automatically calculating and interpolating between the proposed design surface model and positional location provided by GPS. These computers then provide the operators of the heavy equipment with visual guidance as to the horizontal direction to turn the equipment and for the need to cut or fill at specific locations. 
11) Contractors have stated that they can recoup their initial equipment investment within their first large project. Not all dozers, graders and excavators need to have AMG technology on a job, just those who are responsible for ensure the proposed grade surface of a construction operation, and they guide the equipment without the AMG.

12) Contractors are incorporating quality control as part of their daily activities. AMG equipment checks against known positions and elevations routinely to verify the proper calibration. Personnel periodically spot check across grading operations with GPS/RTK rovers to verify that the use of AMG is providing the desired results. This QC activity is what is increasing the contractor's confidence in the reliability of AMG.

13) By the use of AMG, contractors have found they have significantly decreased the waste of time and material which occurs as a part of excavation or embankment operations. This has eliminated the need to remove material in over-filled areas or replace and recompact material in undercut areas. It has also reduced the over-cutting of the sidewall widths needed for water, sewer or storm drainage trenches.

14) Contractors and DOTs are experiencing better quality in the construction of new roadways. Former methods relied on operators to interpolate the grade between stakes, and thus the grade may have only been really accurate at the grade stakes. By use of AMG, the interpolation is automated, thereby the material is placed as accurately as the roadway model has been designed, and smoothness of the riding surface is a function of the density of points used to describe the finished grade of the digital terrain surface. Thus, if the design model has an appropriate density of points, the tangential bumps along a roadway will be smoothed.

15) Contractors would like to use AMG more in the excavation, construction and backfill of bridge substructures and box culverts. Excavating a substructure and associated side slopes by use of an excavator with AMG eliminates undercuts of the proposed footing elevation or inappropriate cutbacks of the side slopes. It also eases the work necessary to place multiple types of backfill material around the completed substructure.

16) Grading operations for difficult-to-construct retention/recharge basins have become much easier to complete with the use of AMG. No stakes are in the way of the grading equipment and side slopes are built as precisely as they are designed.

17) Robotic Total Station and Laser Guided AMG are affected by required line-of-sight, and therefore are less desirable for most operations. They are more precise vertically than GPS and are used for final grading of subbase material.

\section{B. AUTOMATED CONSTRUCTION INSPECTION}

1) This use of technology includes GPS/RTK Rovers for positioning in the field, and may include an attached tablet PC with the Bentley On-Site Inspection software. The GPS Rovers on NYSDOT projects are manufactured primarily by Trimble, Leica or Topcon. 
The Rovers come with handheld PCs which are adequate for data collection, calculation and stakeout, but have limited field of view due to small screen size and smaller processing capability. In many cases the Inspectors taught themselves how to use the data collectors. The addition of the tablet PC with On-Site allows for the graphical display of construction features through a CADD interface, access to attribute information about those features, and the inspection recordkeeping needed to document quantities and approved completed items.

2) GPS is presently provided to inspectors by one of two methods. The Department has acquired a few rovers for each of the regions, but not a sufficient number to meet the expanding need expressed by the regions. GPS is also provided through an item in the contract which includes the rover, modem/radio for connection to the CORS, maintenance on the equipment, training and connections to a DOT provided tablet PC. When a tablet PC is utilized, it is provided through the Department's Seat Management contract by a $3^{\text {rd }}$ party vendor.

3) This inspection technology allows one inspector to complete the work of 2 or 3 over the same time span. One person can verify positional locations, quantities and types of materials without the need of a tape measure, level and rod, or an arm roll of paper plans. That person can move to various locations on the project without having to return to the field office to obtain different paper contract plan sheets.

4) Inspectors appreciate the quick speed at which they can make positional determinations to verify correct locations. They also like the ability to make these positional determinations independent from the contractor's control. They do not have to depend upon contractor's stakes to ensure the correct location, because GPS makes spatial determinations from both satellites and from local corrections to either a base station or the NYS CORS Network.

5) The speed at which spatial determinations can be with GPS increases the safety for the inspectors since they can move in and out of work operations before heavy equipment return to an open area.

6) Inspectors are becoming quite comfortable with GPS once they learn how to use it, understand its limitations, and learn ways to verify that it is providing appropriate answers. Training was the one issue mentioned that needed to be improved upon.

7) Inspectors who had been using the GPS for inspection purposes would not want to give it up on their next construction project. They felt it was very valuable to them for spatial position verification and quantity measurements.

8) The GPS technology provides positional accuracies which meet the needs of most construction specifications, except for concrete or asphalt paving and for bridge superstructures. 
9) Quality Assurance of the spatial positions provided by GPS is verified by routinely measuring and checking the GPS position and elevation of known existing control points.

10) Additional comments besides the need for more training were that larger projects needed additional rovers for the inspectors, and there is room for improvement on the interoperability between the GPS and Bentley's On-Site program. All inspectors agreed that GPS Rovers should be provided for all construction projects which require positional verifications.

11) Initially, most EICs were skeptical of GPS. Since they have seen the contractors and some of the inspectors using it they are changing their view. They want more of them for the inspectors (minimum of 2 per project), and they would like a lower level (mapping grade) model for their use to help visualize where things are in the field (without stakes).

12) Rovers can be used not only to measure quantities, but also to measure and map out a terrain surface. These terrain surfaces can be used to verify if finished surfaces match what was the design surface, and can also be compared against other changed surfaces of the same spatial area to determine volume quantities.

13) Inspectors would benefit from access to a support person with a land surveying background to help them better understand the technical issues associated with establishing project control and localizing it with the GPS Rovers.

14) Inspectors did recommend that the Department needs to document the proper procedures need to obtain accurate and consistently reliable results with the GPS.

15) Assuming the data communication of RTK corrections is not an issue, most DOT Inspectors agreed that use of the NYS CORS as a control network for projects is preferable over the use of contractor provided on-site base stations.

\section{ELECTRONIC ENGINEERING DATA (EED)}

1) The contractors visited on each of these projects requested that Department provide copies of all engineering data electronic format. This includes DTM surfaces, control alignments, profiles, and sections as well as coordinates of all 2D data (nontriangulated), storm \& sanitary database, and graphics of terrain mapping, details, typical sections, record plans and schematics.

2) There is a learning curve for both contractors and DOT personnel to learn how to create DTMs for use by AMG. The motivation for contractors to learn this is initially higher, but they believe the value for the Department will be realized soon. The ability to calculate volume quantities by use of CADD programs provides increased accuracy and faster speed over traditional cross sectional area methods. 
3) An interesting change in culture has been observed in the field by the exchange or sharing of electronic data. This reduces the need to keep 2 sets of information by DOT and the contractor which many times don't agree. This sharing of the same information, which helps to more clearly convey the design intent, has quietly increased the level of trust in the field. This sharing of data also leads to increased consistency of data used, reduced misunderstandings of intent, and will help to avoid some potential claims.

4) Some EICs and contractors would like to be able to share the large project files through the use of ProjectWise over the Internet. Files are too big for email, and it is inconvenient sometimes to mail or exchange CDs or memory sticks.

5) Contractors would like more electronic positional data on the extremities of a bridges substructure. These could be provided as features, with or without alignments. This information could help eliminate some errors that arise with the recalculation and rekeying of control information to be able to stake out the extremities of the foundations, and the locations of any proposed piles.

6) Models from DOT have needed some work to be useable for AMG. The DTM surfaces have been found to:

a. Incomplete - appear to be progressed to an advanced stage, but not completed

b. Multiple Breaklines - duplicative breaklines lying on top of one another

c. Breakline Spacing - need to reduce spacing between proposed breaklines to smooth the finished surface

d. Conflicting Breaklines - breaklines from multiple adjacent alignments overlap and provide conflicting surface elevations

e. Inconsistent Standards - some models do not appear to follow Department CADD Standards or file naming conventions.

7) With electronic data, there are some types of paper data which are no longer needed, for example:

a. Cross sections - computers can create a visual cross section on demand from a model, so paper cross sections are not necessary.

b. Baseline and baseline ties - with the use of GPS, baselines and their ties are no longer needed for stakeout purposes on project providing electronic data.

8) Policy and procedures for documenting and facilitating the exchange of electronic data need to be developed and published as part of the CAM.

9) Contractors believe there would be a big benefit to having positional information on where the volumes of all dirt items are anticipated to be used on a project. This would be most beneficial during the short window of time allowed for bidding a project. With the current minimal information provided in the summaries of earthwork, it is very difficult to bid a price for the work when its location is unknown and its level of difficulty can not be determined. Generally those bid prices are rounded up to reflect that level of uncertainty. 
10) Contractors have found that by the use of $3 D$ terrain surfaces they can identify mistakes or abnormalities in the design before construction begins, thereby fixing the problem before it becomes an issue.

11) One interesting quote stated by a Contractor's Superintendent says a lot about the potential of using electronic engineering data, as follows. "The ambiguity, vagueness or misconceptions built into utilizing 2D paper plans instead of a 3D design model allows for interpretation by the contractor of the designer's intent which he/she will naturally use to their advantage (as any profit motivated business person would do). The more precisely detailed (or modeled) the design of a project, the less chance of misinterpretation of intent, the more precisely it will be constructed by AMG, and the more accurately it can be inspected to verify the appropriate position.” 


\begin{tabular}{|c|c|c|c|c|c|c|}
\hline State & $\begin{array}{l}\text { Provision for } \\
\text { EF }\end{array}$ & $\begin{array}{l}\text { Guide Files } \\
\text { Provided }\end{array}$ & $\begin{array}{l}\text { DTM } \\
\text { Provisions }\end{array}$ & $\begin{array}{c}\text { EF } \\
\text { Submission }\end{array}$ & $\begin{array}{l}\text { EF Signed } \\
\text { Files }\end{array}$ & Notes \\
\hline Alabama & Yes & Yes & Yes (1) & Yes & Not Found & Acccount required for online delive \\
\hline Alaska & No & Some & No & No & No & \\
\hline Arizona & Yes & None Found & Yes & Via ftp or CD & Not Found & \\
\hline Arkansas & $?$ & Yes & & & & \\
\hline California & Yes & Yes & $?$ & Yes & Unknown & \\
\hline Colorado & Yes & Yes & Yes & see note & No & Working on standards as of 12 July 2006 \\
\hline Connecticut & Yes & Yes & None found & Yes & No & \\
\hline Delaware & Yes & & & & & $\begin{array}{r}\text { EDF's are not considered official plans, but can be provided to } \\
\text { the contractor for convenience }\end{array}$ \\
\hline Florida & Yes & & & Yes & Yes & $\begin{array}{r}\text { Uses SHA-1 hash code to authenticate through a program } \\
\text { named PEEDS }\end{array}$ \\
\hline Georgia & Yes & Yes & see note & via $C D$ & No & State has one, but no apparent requirement for submission \\
\hline Hawaii & Yes & None Found & None found & Yes (3) & No & \\
\hline Idaho & Yes & Yes & None found & Yes & No & \\
\hline Illinois & Yes & Yes & None found & Yes, online & Not Found & \\
\hline Indiana & Yes & Yes & None found & None found & No & \\
\hline lowa & Yes & Yes & Yes & Yes & Not Found & $\begin{array}{r}\text { Developmental Specifications in place for GPS Machine } \\
\text { Control grading (DS-01077) }\end{array}$ \\
\hline Kansas & Yes & Yes & None found & see note & & $\begin{array}{r}\text { Much of their resource download database requires a } \\
\text { username and password }\end{array}$ \\
\hline Kentucky & Yes & Yes & Yes (1) & Yes & In progress & Mylar still required as official plans \\
\hline Louisiana & Yes & (4) & Yes & Yes & (5) & \\
\hline Maine & Yes & Yes & None found & No & No & Most CADD pages have not been updated since May 2004 \\
\hline Maryland & Yes & Yes & None found & Yes & Not Found & EDF submission via ProjectWise \\
\hline Massachusetts & Yes & Yes & No & No & No & \\
\hline Michigan & Yes & Yes & Yes (6) & Yes, via PDF & Yes & $\begin{array}{r}\text { Allow submission of a scanned signed title page, replacing title } \\
\text { sheet }\end{array}$ \\
\hline Minnesota & Yes & Yes & Yes & Yes & Not Found & \\
\hline Mississippi & Yes & Yes & No & None found & Not Found & $\begin{array}{l}\text { Evaluate the Use of GPS and Terrain Modeling in Conjunction } \\
\text { with Plan Distribution and Construction listed as a Research } \\
\text { Priority }\end{array}$ \\
\hline Misouri & Yes & Yes & Yes & via $C D$ & No & \\
\hline Montana & Yes & Yes & Yes & via CD & No & Submittal includes CD with hard copies \\
\hline Nebraska & Yes & Yes & None found & No & No & \\
\hline Nevada & Yes & Yes & None found & No & No & \\
\hline New Hampshire & Yes & Yes & No & No & No & \\
\hline
\end{tabular}




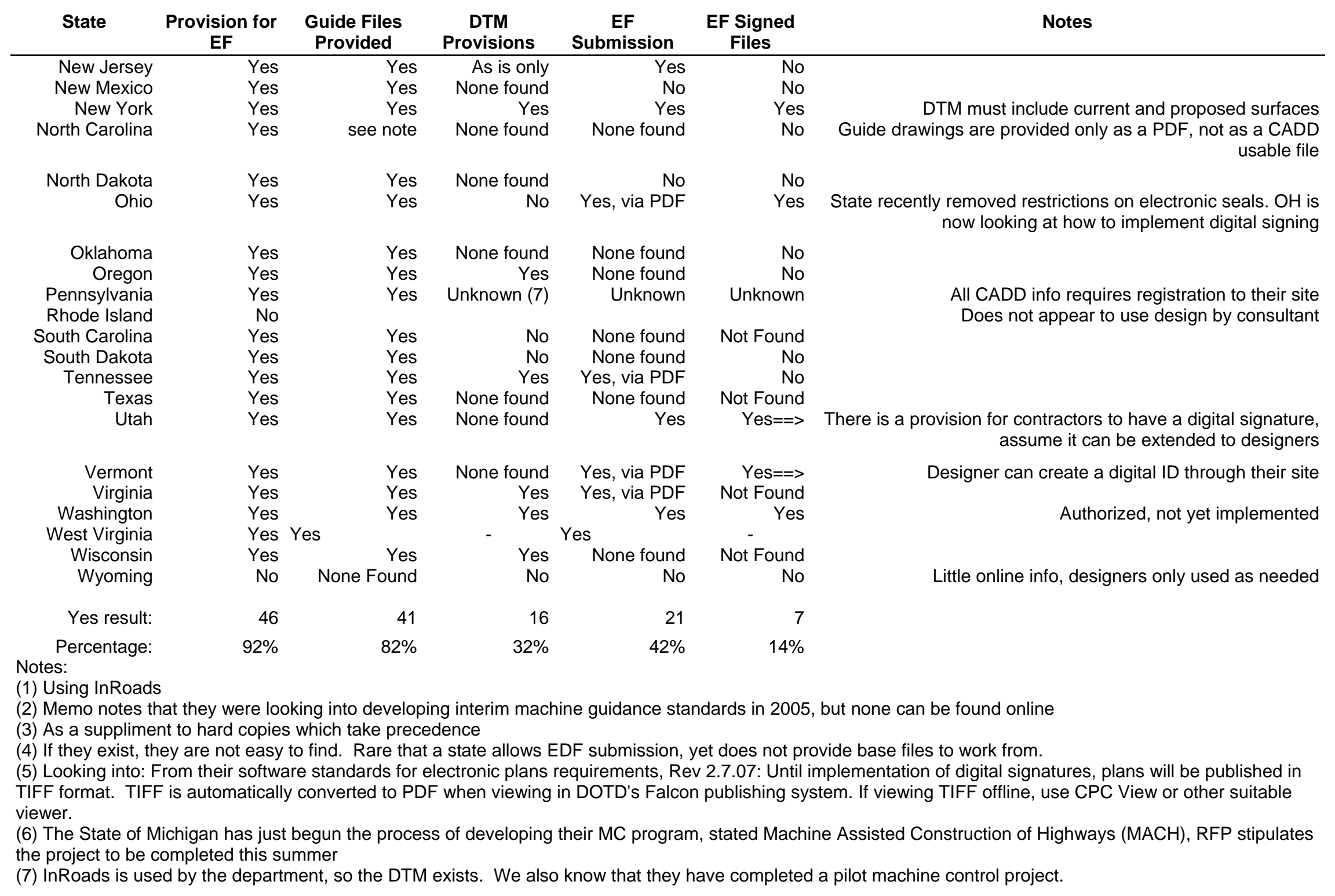

